\title{
Intracellular Calcium Oscillations in Astrocytes: A Highly Plastic, Bidirectional Form of Communication between Neurons and Astrocytes In Situ
}

\author{
Lucia Pasti, ${ }^{1}$ Andrea Volterra, ${ }^{2}$ Tullio Pozzan, ${ }^{1}$ and Giorgio Carmignoto ${ }^{1}$ \\ ${ }^{1}$ Department of Experimental Biomedical Sciences and Consiglio Nazionale delle Ricerche Center for Biomembranes, \\ University of Padova, 35121 Padova, Italy, and 2Institute of Pharmacological Sciences, University of Milan, 20133 \\ Milan, Italy
}

The spatial-temporal characteristics of intracellular calcium $\left(\left[\mathrm{Ca}^{2+}\right]_{\mathrm{i}}\right)$ changes elicited in neurons and astrocytes by various types of stimuli were investigated by means of confocal fluorescent microscopy in acute rat brain slices loaded with the $\mathrm{Ca}^{2+}$ indicator indo-1. Neurons and astrocytes from the visual cortex and CA1 hippocampal region were identified in situ on the basis of their morphological, electrophysiological, and pharmacological features. We show here that stimulation of neuronal afferents triggered periodic $\left[\mathrm{Ca}^{2+}\right]_{\mathrm{i}}$ oscillations in astrocytes. The frequency of these oscillations was under a dynamic control by neuronal activity as it changed according to the pattern of stimulation. After repetitive episodes of neuronal stimulation as well as repetitive stimulation with a metabotropic glutamate receptor agonist, astrocytes displayed a long-lasting increase in $\left[\mathrm{Ca}^{2+}\right]_{i}$ oscillation frequency. Oscillating astrocytes were accompanied by repetitive $\left[\mathrm{Ca}^{2+}\right]_{i}$ elevations in adjacent neurons, most likely because of the release of glutamate via a tetanus toxin-resistant process. These results reveal that $\left[\mathrm{Ca}^{2+}\right]_{\mathrm{i}}$ oscillations in astrocytes represent a highly plastic signaling system that underlies the reciprocal communication between neurons and astrocytes.

Key words: astrocytes; metabotropic glutamate receptor; intracellular calcium oscillations; synaptic plasticity; neurotransmitter release; hippocampus; visual cortex; tetanus toxin; confocal microscopy
Changes in the intracellular calcium concentration $\left(\left[\mathrm{Ca}^{2+}\right]_{\mathrm{i}}\right)$ mediate a variety of biological responses in both excitable and nonexcitable cells. In the CNS the mechanism of calcium signaling has been investigated extensively in neurons (Ghosh and Greenberg, 1995), whereas less attention has been granted to other CNS cells such as glial cells (but see Barres, 1991). Recent studies, however, revealed that various stimuli, including neurotransmitters, induced in astrocytes $\left[\mathrm{Ca}^{2+}\right]_{\mathrm{i}}$ oscillations and waves propagating from astrocyte to astrocyte via gap junctions (Cornell-Bell et al., 1990; Glaum et al., 1990; Verkhratsky and Kettenmann, 1996). Although the mechanism underlying $\left[\mathrm{Ca}^{2+}\right]_{i}$ oscillations is relatively well defined (Berridge, 1993), little is known about their physiological role. An interesting hypothesis is that the action of $\mathrm{Ca}^{2+}$ as a second messenger in cells displaying $\left[\mathrm{Ca}^{2+}\right]_{\mathrm{i}}$ oscillations may be expressed via a frequency- rather than an amplitude-dependent code (Woods et al., 1986; Jacobs, 1990). This mechanism ensures that the information carried by the intensity of the stimulus is preserved and converted into a defined frequency of oscillations. In astrocytes, $\left[\mathrm{Ca}^{2+}\right]_{\mathrm{i}}$ increases probably regulate features such as the glycogenolysis (Tsacopoulos and Magistretti, 1996) and the synthesis and/or release of arachidonic

Received May 19, 1997; revised July 14, 1997; accepted Aug. 6, 1997.

This work was supported by Grants from Telethon number 845, the European Union Programs-Human Capital and Mobility Network CHRXCT940500, the Human Frontier Science Program RG520/95, the Italian University Ministry, Fidia Research Laboratories, and Biotechnology Program BIO4CT960382. We thank Drs. Aldebaran Hofer and Rosario Rizzuto for critically reading this manuscript. We also thank Dr. Cesare Montecucco for the generous gift of the purified tetanus toxin. Correspondence should be addressed to Dr. Giorgio Carmignoto, Department of Experimental Biomedical Sciences, University of Padova, Viale G. Colombo 3, 35121 Padova, Italy.

Copyright (C) 1997 Society for Neuroscience $\quad 0270-6474 / 97 / 177817-14 \$ 05.00 / 0$ acid (Seregi et al., 1987), neurotransmitters (Pin and Bockaert, 1989; Szatkowski et al., 1990; Gallo et al., 1991), and neurotrophins (Martin, 1992; Zafra et al., 1992).

$\left[\mathrm{Ca}^{2+}\right]_{\mathrm{i}}$ oscillations and waves in astrocytes can be triggered by neuronal activity in primary cortical cultures (Murphy et al., 1993) as well as in cultured brain slices (Dani et al., 1992), although they were not observed in acute brain slices (Porter and Mc Carthy, 1996). After stimulation with bradykinin, cultured astrocytes can trigger significant elevations of the $\left[\mathrm{Ca}^{2+}\right]_{i}$ in neurons (Parpura et al., 1994a). This action is proposed to be mediated by either a calcium-dependent release from astrocytes (Parpura et al., 1994a; Jeftinija et al., 1996) or gap junction communication between astrocytes and neurons (Nedergaard, 1994). Active interactions may, therefore, exist between neurons and astrocytes, at least in culture (Pfrieger and Barres, 1996). The role of astrocytes as passive cells has been disputed further by the observation that cultured astrocytes display a surprising form of cellular memory (Pasti et al., 1995). After repetitive episodes of stimulation with glutamate, the frequency of $\left[\mathrm{Ca}^{2+}\right]_{i}$ oscillations increased drastically (Pasti et al., 1995). The potentiation of the response was long-lasting and involved the activation of a metabotropic glutamate receptor (mGluR) subtype linked to the production of inositol trisphosphate.

Although these observations from cells in culture suggest an active participation of astrocytes in brain functions, an understanding of their role in the neural network requires experiments that are performed in intact tissue preparations. The aim of this study was to investigate whether a communication system exists between neurons and astrocytes in the developing brain. Astrocytes and neurons from hippocampal CA1 region and visual cortex were identified in acute brain slice preparations on the 
basis of their morphological, electrophysiological, and pharmacological features. The spatial-temporal features of their $\left[\mathrm{Ca}^{2+}\right]_{1}$ changes were investigated after various stimuli, including neuronal stimulation. A confocal fluorescence microscope in conjunction with the calcium indicator indo-1 was used to monitor $\left[\mathrm{Ca}^{2+}\right]_{\mathrm{i}}$ changes at the single-cell level.

We here demonstrate a long-term change in $\left[\mathrm{Ca}^{2+}\right]_{i}$ oscillation frequency in astrocytes in response to repetitive episodes of neuronal stimulation as well as to successive applications of the mGluR agonist 1-aminocyclopentane-1,3-dicarboxylic acid ( $t$ ACPD). In addition, we provide compelling, although indirect, evidence that activation of the $\mathrm{mGluR}$ triggers the release of glutamate that, in turn, induces $\left[\mathrm{Ca}^{2+}\right]_{\mathrm{i}}$ oscillations in neighboring neurons.

\section{MATERIALS AND METHODS}

Slice preparation for confocal microscopy. Transverse brain slices (150$250 \mu \mathrm{m})$ from both the visual cortex and the hippocampus were prepared from Wistar rats at postnatal days 7-12, as previously described (Edwards et al., 1989; Carmignoto and Vicini, 1992). Slices were incubated in physiological saline containing $20 \mu \mathrm{M}$ indo-1/AM (Molecular Probes, Eugene, OR) and $0.02 \%$ pluronic acid at $37^{\circ} \mathrm{C}$ for $40-50$ min under continuous mild stirring. Following the evidence that antioxidant agents can protect neurons from degeneration (Rice et al., 1994), the physiological saline for slice incubation was as follows (in $\mathrm{mm}$ ): $\mathrm{NaCl} 120, \mathrm{KCl}$ 3.1, $\mathrm{NaH}_{2} \mathrm{PO}_{4} 1.25, \mathrm{NaHCO}_{3} 25$, dextrose $4, \mathrm{MgCl}_{2} 2, \mathrm{CaCl}_{2} 1$, Napyruvate 2, myo-inositol 0.5 , and ascorbic acid 0.1 at $\mathrm{pH} 7.4$ with $5 \% \mathrm{CO}_{2} / 95 \% \mathrm{O}_{2}$.

Ratio image acquisition. Recording sessions were performed at room temperature. After incubation with indo-1/AM, slices were mounted in a chamber that was placed on the stage of a Nikon inverted microscope (Diaphot 300), equipped with a $40 \times$ water immersion objective, numerical aperture 1.1 (Nikon), connected with a real time confocal microscope (Nikon, RCM8000). The $351 \mathrm{~nm}$ band of the argon ion laser was used for excitation, and the emitted light, separated into its two components (405 and $485 \mathrm{~nm}$ ) by a dichroic mirror, was collected by two separate photomultipliers. The ratio of the intensity of the light emitted at the two wavelengths $(405 / 485)$ was displayed as a pseudocolor scale. Time series were acquired with a frame interval of 1,2 , or $3 \mathrm{sec}$, and 16 images were averaged for each frame. During recordings, slices were perfused continuously $(3 \mathrm{ml} / \mathrm{min})$ with physiological saline of the following composition (in mM): $\mathrm{NaCl} 120, \mathrm{KCl} 3.1, \mathrm{NaH}_{2} \mathrm{PO}_{4} 1.25, \mathrm{NaHCO}_{3} 25$, dextrose $5, \mathrm{MgCl}_{2} 1$, and $\mathrm{CaCl}_{2} 2$ at $\mathrm{pH} 7.4$ with $5 \% \mathrm{CO}_{2} / 95 \% \mathrm{O}_{2}$. The $\mathrm{R} 405 / 485$ in basal conditions was observed to vary little in different cells. Occasionally, a slight decrease was observed in R405/485 basal levels (see, for example, Fig. $7 A$ ). Indeed, prolonged UV irradiation of indo- 1 can cause overall photobleaching and conversion to a fluorescent, but $\mathrm{Ca}^{2+}$. insensitive, species (Scheenen et al., 1996). In several experiments we used $100 \mu \mathrm{M}$ Trolox, a vitamin E analog that inhibits the formation of indo-1 photodegradation products (Scheenen et al., 1996). No substantial differences, however, were observed in our conditions. The frequency of oscillations is expressed as the number of $\left[\mathrm{Ca}^{2+}\right]_{i}$ peaks per minute.

Stimulation protocols. To investigate the role of extracellular $\mathrm{Ca}^{2+}$, at $5 \mathrm{~min}$ before the onset of the $t$-ACPD stimulation, we perfused slices with a $\mathrm{Ca}^{2+}$-free physiological saline supplemented with $1 \mathrm{~mm}$ EGTA. The stimulation with high $\mathrm{K}^{+}$extracellular solution was obtained by isosmotic replacement of $\mathrm{Na}^{+}$with $\mathrm{K}^{+}$. Changes of $\left[\mathrm{Ca}^{2+}\right]_{i}$ because of synaptic activity were evoked by stimulus trains consisting of $50 \mu \mathrm{sec}$ pulses at $20-30 \mathrm{~Hz}$ for $100-200 \mathrm{msec}$ delivered through an isolation unit (World Precision Instruments, Sarasota, FL) to a bipolar tungsten electrode (5 $\mu \mathrm{m}$ tip, Roboz, Rockville, MD) positioned either intracortically or at the white-matter/layer VI border, in the case of the visual cortex, and at the stratum radiatum to stimulate the Schaffer collateral-commissural pathway, in the case of the hippocampus. The electrode was positioned at $150-500 \mu \mathrm{m}$ from the cells of interest. To optimize the response, we often found it necessary to move the stimulating electrode in different positions, but once it was established, the electrode was not moved further for the duration of the experiment. The stimulus was applied at various frequencies $(0.1-1 \mathrm{~Hz})$ and amplitudes $(50-500 \mathrm{pA})$.

Electrophysiological recordings. Brain slice preparation was performed as previously described (Carmignoto and Vicini, 1992). In the holding chamber, slices were perfused continuously $(3-5 \mathrm{ml} / \mathrm{min})$ with the same saline used for recording at the confocal microscope. The patch-clamp technique (Edwards et al., 1989) was used in the whole-cell recording configuration. Cells were viewed with an upright Zeiss Axioskop microscope equipped with differential interference contrast (DIC), Nomarski optics (UEM, Zeiss, Oberkochen, Germany), and an electrically insulated water immersion $40 \times$ objective with a long working distance $(2$ $\mathrm{mm})$. Electrodes were pulled in two stages on a vertical pipette puller from borosilicate glass capillaries (Wiretrol II, Drummond, Broomall, PA). Typical pipette resistance was 5-10 M $\Omega$. Intracellular (patch pipette) solutions contained (in $\mathrm{mM}$ ): $\mathrm{KCl}$ or K-gluconate $145, \mathrm{MgCl}_{2} 1$, Mg-ATP 2.0, and HEPES 10 to $\mathrm{pH} 7.2$ with $\mathrm{KOH}$. Indo-1-free acid was included in the patch pipette at $500 \mu \mathrm{M}$ concentration. The intracellular solution was filtered with a 0.22 pore size filter (Millipore, Yonezawa, Japan). Recordings for 3-5 min were sufficient to obtain the loading of indo- 1 in thin processes of both neurons and astrocytes. A rest of $\sim 30$ min was allowed before visualization of the cell at the confocal microscope. Recordings were performed in current clamp and voltage clamp with a patch-clamp amplifier (EPC 7, List Electronics, Darmstadt, Germany), sampled at 10 or $20 \mathrm{kHz}$, filtered at $1.5 \mathrm{kHz}$ (eight-pole low-pass Bessel filter; Frequency Devices, Haverhill, MA), and digitized by the interface Digidata 1200A and pCLAMP-6 software (Axon Instruments, Foster City, CA). In the current-clamp mode depolarizing and hyperpolarizing current pulses of increasing amplitude and 100-500 msec duration were applied to elicit action potential firing from the recorded cells. The inhibitory action of tetanus neurotoxin (TeNT) on synaptic transmission was investigated in CA1 hippocampal region by recording EPSCs evoked by stimuli consisting of $50 \mu \mathrm{sec}$ pulses $(50-200 \mu \mathrm{A}$ at $0.2 \mathrm{~Hz}$ ) applied through a bipolar tungsten electrode ( $5 \mu \mathrm{m}$ tip, Roboz) to the Schaffer collaterals before and during slow perfusion $(1 \mathrm{ml} / \mathrm{min})$ with 100 $\mu \mathrm{M}$ TeNT. Once the whole-cell configuration was achieved and before the onset of the TeNT perfusion, the intensity and duration of the stimulus eliciting the EPSC were adjusted to obtain a stable baseline of synaptic responses. In control neurons from slices perfused at $1 \mathrm{ml} / \mathrm{min}$, EPSCs were still present after $30 \mathrm{~min}$ recordings. Origin (MicroCal Software, Northampton, MA) was used for data analysis and figure preparation.

Drugs. Excitatory amino acid receptor antagonists 4-carboxyphenylglycine (4CPG), L(+)-2-amino-3-phosphonopropionic acid (L-AP3), 1aminoindan-1,5-dicarboxylic acid (AIDA), $\alpha$-methyl-4-carboxyphenylglycine (MCPG), 2-amino-5-phosphonopentanoic acid (D-AP5), 6-nitro-7sulfamoylbenzo[f]quinoxaline-2,3-dione (NBQX), and $t$-ACPD were obtained from Tocris Cookson (Buckhurst Hill, UK), dissolved in $\mathrm{NaOH}$ or DMSO, and diluted in the physiological saline used for recordings. Purified TeNT (Schiavo and Montecucco, 1995) was a gift from C. Montecucco (Department of Experimental Biomedical Sciences, University of Padova, Italy).

\section{RESULTS}

\section{Activation of mGluRs induces $\left[\mathrm{Ca}^{2+}\right]_{i}$ increases in different cell types from developing hippocampus and visual cortex}

Acute brain slices from the hippocampus and the visual cortex were loaded with the fluorescent $\mathrm{Ca}^{2+}$ indicator indo- 1 by using the cell-permeant acetoxymethyl derivative and were analyzed by laser scanning confocal microscopy. As illustrated in Figure $1 \mathrm{~A}$, pyramidal neurons from CA1 hippocampal region were well loaded and can be distinguished clearly by their typical shapes and the large size of their somas. Small cells with a stellate shape, like cells labeled 1 and 2, also were well loaded with indo-1 but could not be classified unambiguously solely on the basis of their morphological features. The series of pseudocolor images in Figure $1 A$ illustrates the effects on the $\left[\mathrm{Ca}^{2+}\right]_{\mathrm{i}}$ induced on these cells by application of the mGluR agonist $t$-ACPD ( $5 \mu \mathrm{M}$; Palmer et al., 1989). Small cells like cells 1 and 2, as well as two of the pyramidal neurons labeled 3 and 4 , displayed a $\left[\mathrm{Ca}^{2+}\right]_{i}$ transient on $t$-ACPD addition. The kinetics of the $\left[\mathrm{Ca}^{2+}\right]_{\mathrm{i}}$ changes, as expressed by the ratio between indo- 1 emission at 405 and 485 $\mathrm{nm}$, on continuous exposure to $t$-ACPD are reported in Figure $1 C$ (left) and reveal the presence of periodic $\left[\mathrm{Ca}^{2+}\right]_{\mathrm{i}}$ oscillations in small cells 1 and 2 (green and red traces), whereas the pyramidal 
A
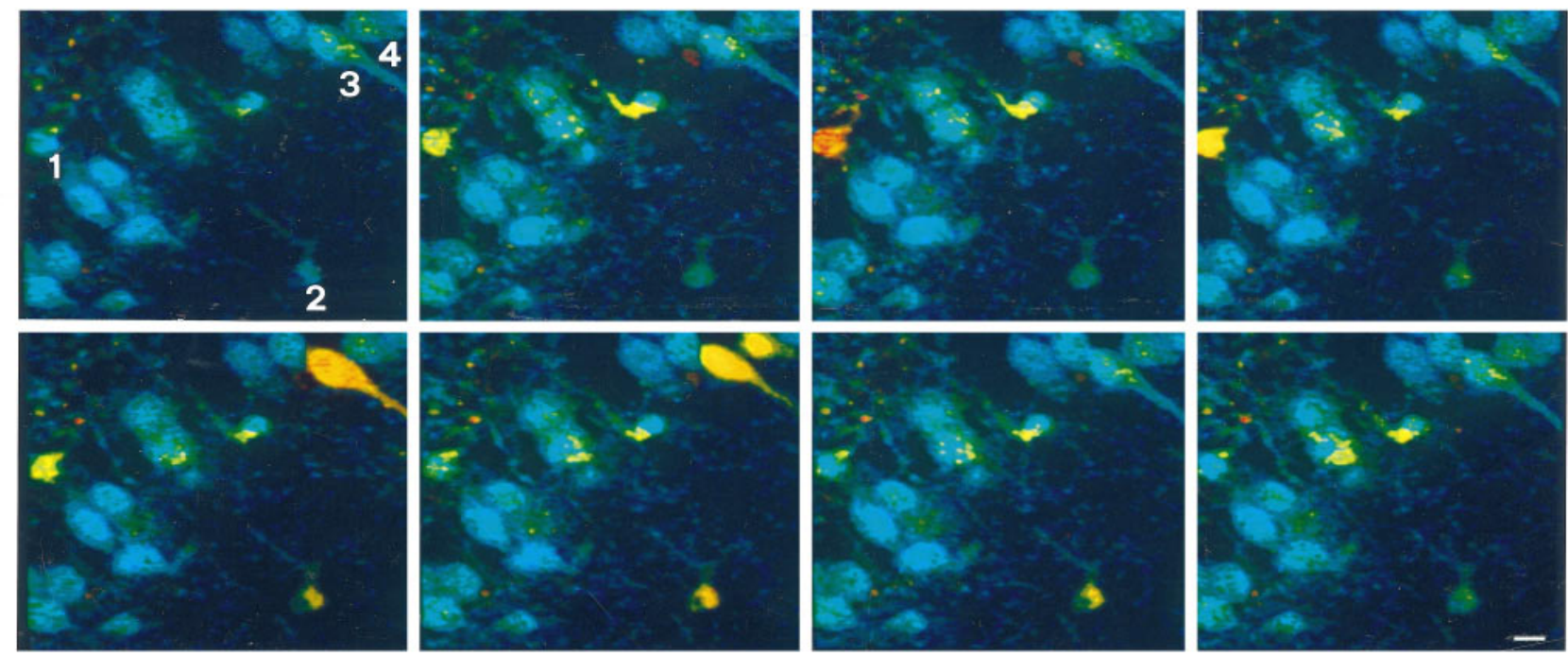

B
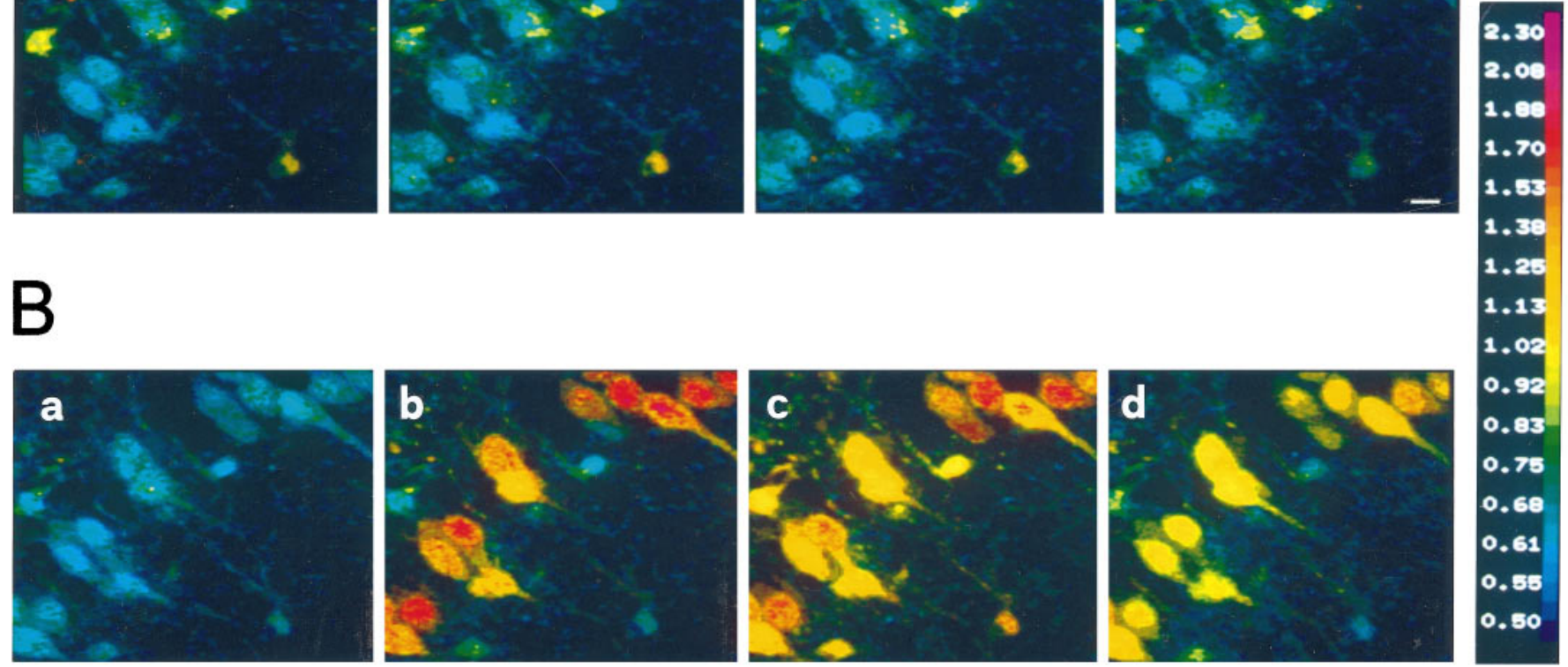

C

\section{1, 2 astrocytes}

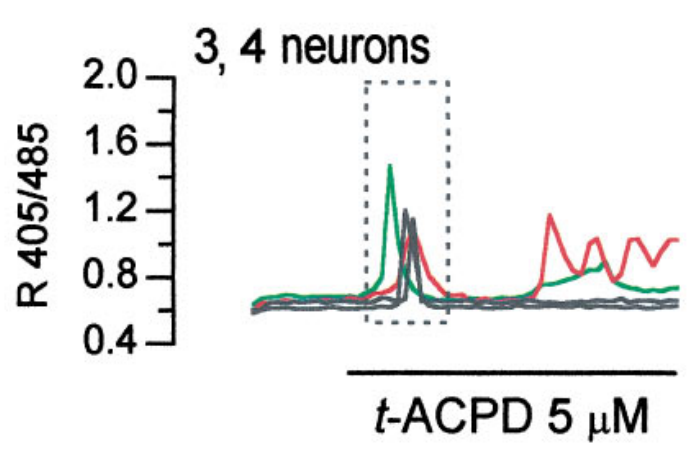

$\mathrm{KCl} 60 \mathrm{mM}$

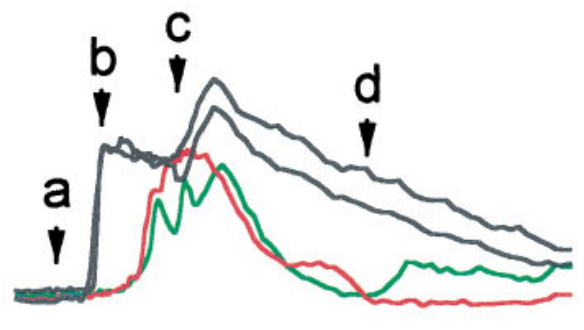

R 405/485

Figure 1. Stimulation of mGluRs induces $\left[\mathrm{Ca}^{2+}\right]_{\mathrm{i}}$ oscillations in hippocampal cells. $A$, Time series of pseudocolor images of the $\left[\mathrm{Ca}{ }^{2+}\right]_{\mathrm{i}}$ changes occurring in indo-1-loaded cells from CA1 hippocampal region of a young rat (at postnatal day 8) after perfusion of the slice with $5 \mu \mathrm{M} t$-ACPD. The sequence shows the $\left[\mathrm{Ca}^{2+}\right]_{\mathrm{i}}$ transient in two small-sized cells (labeled 1 and 2) and two pyramidal neurons (labeled 3 and 4 ). The $R 405 / 485$ is displayed as a pseudocolor scale. Sampling rate, $3 \mathrm{sec}$; scale bar, $10 \mu \mathrm{m}$. $B$, Pseudocolor images $(a-d)$ from the same field illustrating the early, sustained $\left[\mathrm{Ca}^{2+}\right]_{\mathrm{i}}$ increase in neurons, including neurons labeled 3 and 4 in $A$, and the transient, delayed response in small cells, including cells labeled 1 and 2 in $A$, after bath application of $60 \mathrm{~mm} \mathrm{KCl}$. Symbols and conditions are as in $A$. $C$, Kinetics of the $\left[\mathrm{Ca}^{2+}\right]_{\mathrm{i}}$ changes in the cells labeled $1-4$ after $t$-ACPD and $\mathrm{KCl}$ stimulation, as expressed by the ratio between indo-1 emission wavelength at 405 and $485 \mathrm{~nm}$. Letters $a-d$ correspond to images $a-d$ in $B$.

neurons (cells 3 and 4) displayed a single transient peak (black traces). A delayed response also was observed in six additional neurons in the field. In two of these the pattern of the response was oscillatory (data not shown). In a series of comparable experiments from CA1 region, the pyramidal neurons responding to $t$-ACPD (ranging from 2 to $10 \mu \mathrm{M}$ in the various experiments) were $68.7 \pm 8.9 \%$ (mean $\pm \mathrm{SE}$; range 17-100), and small cells were $76.3 \pm 3.7 \%$ (range 52-100). In a few experiments from both hippocampus and visual cortex, concentrations higher than $10 \mu \mathrm{M}$ were tested also. At $t$-ACPD concentrations of $50-100 \mu \mathrm{M}$ the 
probability of observing $\left[\mathrm{Ca}^{2+}\right]_{i}$ oscillations decreased, and most of the cells displayed a $\left[\mathrm{Ca}^{2+}\right]_{\mathrm{i}}$ rise, followed by a slowly decreasing plateau, suggesting that $\left[\mathrm{Ca}^{2+}\right]_{i}$ oscillations were critically dependent on the concentration of $t$-ACPD. In the experiments described below, for the analysis of $\left[\mathrm{Ca}^{2+}\right]_{\mathrm{i}}$ oscillations we used $t$-ACPD concentrations between 2 and $10 \mu \mathrm{M}$.

\section{Astrocyte identification}

Small cells displaying $\left[\mathrm{Ca}^{2+}\right]_{\mathrm{i}}$ oscillations from both visual cortex and hippocampal $\mathrm{CA} 1$ and stratum radiatum regions had an astrocyte-like morphology with a mean soma diameter of 5-10 $\mu \mathrm{m}$ and numerous radiating processes. These cells could be distinguished easily from pyramidal neurons. On the basis of pure morphological criteria, however, astrocytes hardly can be distinguished from small nonpyramidal neurons with a stellate or bipolar shape that are present in both areas (Ramon y Cajál, 1911). We first tried to identify astrocytes via glial fibrillary acidic protein (GFAP) immunostaining performed at the end of the recording session at the confocal microscope. Several cells with astrocyte-like morphology that displayed $\left[\mathrm{Ca}^{2+}\right]_{i}$ oscillations in response to $t$-ACPD could, indeed, be identified retrospectively as astrocytes by anti-GFAP immunostaining. Because of the variability in the intensity of the GFAP staining in different slices and among cells and to the overall alteration in the cell morphology after fixation and permeabilization procedures, in $<10 \%$ of the cells in the recording field was the identification unambiguous. An alternative approach thus was developed to distinguish functionally each astrocyte and neuron present in the recording field. The experiments described below refer to CA1 hippocampal region, although identical results were obtained in the visual cortex. We took advantage of the observation that, in mixed neuron-astrocyte cultures, neurons, as identified by immunocytochemical criteria, responded promptly with a $\left[\mathrm{Ca}^{2+}\right]_{i}$ increase to depolarization induced by $60 \mathrm{~mm} \mathrm{~K}^{+}$, whereas none of the immunocytochemically identifiable astrocytes was sensitive to this treatment (data not shown). We thus applied the same protocol to brain slices to analyze whether neurons and presumed astrocytes responded differently, as in culture, to stimulation with $60 \mathrm{mM} \mathrm{K}^{+}$. As shown in Figure $1 B$, in response to this treatment all cells in the field showed large $\left[\mathrm{Ca}^{2+}\right]_{\mathrm{i}}$ increases. The onset of the response from the two cell populations was, however, clearly different. In the first population, mainly composed of cells with an evident pyramidal shape, the perfusion with high $\mathrm{K}^{+}$induced a prompt $\left[\mathrm{Ca}^{2+}\right]_{\mathrm{i}}$ increase (Fig. $1 \mathrm{Bb}$ ). In the majority of neurons this first increase was followed by a further $\left[\mathrm{Ca}^{2+}\right]_{\mathrm{i}}$ elevation (Fig. $1 C$, right). In the second population, composed of smallsized cells with astrocyte-like morphology, the $\left[\mathrm{Ca}^{2+}\right]_{i}$ increase occurred many seconds $(13.3 \pm 1.6 \mathrm{sec}$; mean $\pm \mathrm{SE} ; n=5)$ after that of pyramidal neurons at approximately the same time of the second $\left[\mathrm{Ca}^{2+}\right]_{\mathrm{i}}$ peak in neurons (Fig. $1 B c, C$, right). A delay in the response to $60 \mathrm{mM} \mathrm{K}^{+}$was never observed in cells having a pyramidal shape. The kinetics of the recovery were also different: in cells that displayed the prompt response to depolarization, the $\left[\mathrm{Ca}^{2+}\right]_{\mathrm{i}}$ remained elevated for several minutes and recovered to basal levels quite slowly, whereas in cells that displayed the delayed response the kinetics of the $\left[\mathrm{Ca}^{2+}\right]_{\mathrm{i}}$ decrease were faster,

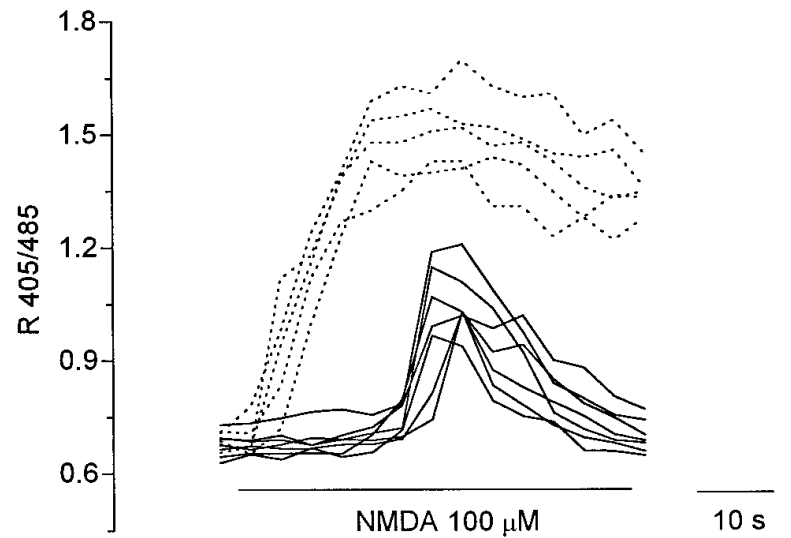

Figure 2. Kinetics of $\left[\mathrm{Ca}^{2+}\right]_{\mathrm{i}}$ in cells from the visual cortex in response to NMDA. Presumed astrocytes $(n=7$; solid lines $)$ from the visual cortex of a 5-d-old rat display a delayed $\left[\mathrm{Ca}^{2+}\right]_{\mathrm{i}}$ increase to NMDA $(100 \mu \mathrm{M})$ with respect to the prompt response of pyramidal neurons $(n=5$; dashed lines).

and basal $\left[\mathrm{Ca}^{2+}\right]_{\mathrm{i}}$ levels were recovered in $\sim 40 \mathrm{sec}$ (Fig. $1 B d, C$, right). Occasionally, these cells displayed repetitive $\left[\mathrm{Ca}^{2+}\right]_{\mathrm{i}}$ transients that resemble the typical $t$-ACPD-induced $\left[\mathrm{Ca}^{2+}\right]_{\mathrm{i}}$ oscillations (data not shown). A delayed response pattern is consistent with a secondary response to glutamate massively released by depolarized synaptic terminals. Indeed, the response of smallsized cells, but not that of pyramidal neurons, to the stimulation with $60 \mathrm{~mm} \mathrm{~K}{ }^{+}$was blocked in slices incubated for $40 \mathrm{~min}$ in TeNT $(100 \mu \mathrm{g} / \mathrm{ml})$, a well known, potent inhibitor of neuronal exocytosis (data not shown; see Fig. $7 E$ ). Given that all neurons express at least one subtype of functional voltage-gated $\mathrm{Ca}^{2+}$ channels, the delayed response to $60 \mathrm{mM} \mathrm{K}^{+}$could be attributed only to non-neuronal cells, such as astrocytes, that either lack these channels or express voltage-gated $\mathrm{Ca}^{2+}$ channels at such low density (Barres et al., 1990) to induce negligible $\left[\mathrm{Ca}^{2+}\right]_{\mathrm{i}}$ increases, at least under our experimental conditions. We also stimulated slices with $100 \mu \mathrm{M}$ NMDA. Given that NMDA receptors in astrocytes are most likely absent or nonpermeable to $\mathrm{Ca}^{2+}$ (Müller et al., 1993), NMDA should induce a $\left[\mathrm{Ca}^{2+}\right]_{\mathrm{i}}$ increase in neurons, whereas astrocytes either should not respond or should display a delayed $\left[\mathrm{Ca}^{2+}\right]_{\mathrm{i}}$ increase because of a secondary release of glutamate. Stimulation with NMDA $(100 \mu \mathrm{M})$ induced in the two populations a pattern of $\left[\mathrm{Ca}^{2+}\right]_{\mathrm{i}}$ increase similar to that observed after perfusion with $60 \mathrm{~mm} \mathrm{~K}^{+}$(Fig. 2). Interestingly, NMDA did not induce the biphasic response observed after depolarization with high $\mathrm{K}^{+}$. This latter finding supports the hypothesis that the second peak in the $\left[\mathrm{Ca}^{2+}\right]_{\mathrm{i}}$ increase induced in neurons by high $\mathrm{K}^{+}$stimulation is attributable to glutamate released by depolarized terminals.

To confirm that this type of response pattern can be used as a functional tool to identify astrocytes in situ, we first distinguished neurons and astrocytes on the basis of their biophysical properties by patch-clamp recording while indo- 1 diff used into the cell through the patch pipette. Then the pipette was gently withdrawn, and the $\left[\mathrm{Ca}^{2+}\right]_{\mathrm{i}}$ response finally was ana-

Figure 3. Functional identification of small-sized cells and pyramidal-shaped cells from CA1 hippocampal region as astrocytes and neurons, respectively. $A$, Pseudocolor image illustrating one pyramidal neuron and one astrocyte (white arrows) from CA1 hippocampal region of a 10-d-old rat injected with indo-1-free acid included in the patch pipette at $500 \mu \mathrm{m}$. This image was taken at the end of the recording session at the confocal microscope, using high laser power to permit visualization of four astrocytes (black arrows) dye-coupled with the injected astrocyte. This accounts (Figure legend continues) 
A

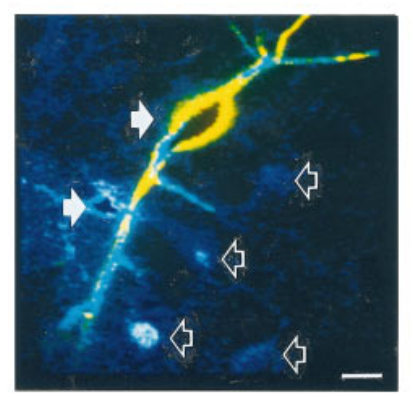

B

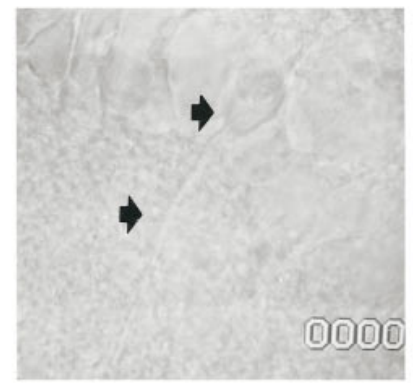

C

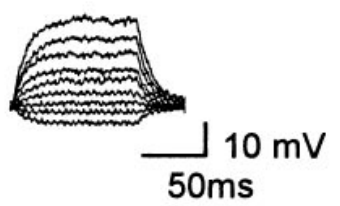

D

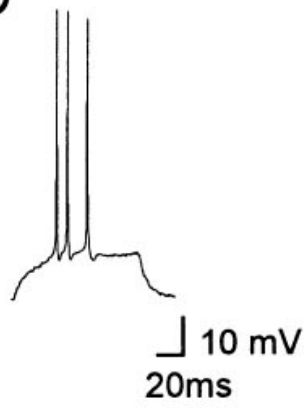

$\mathrm{E}$
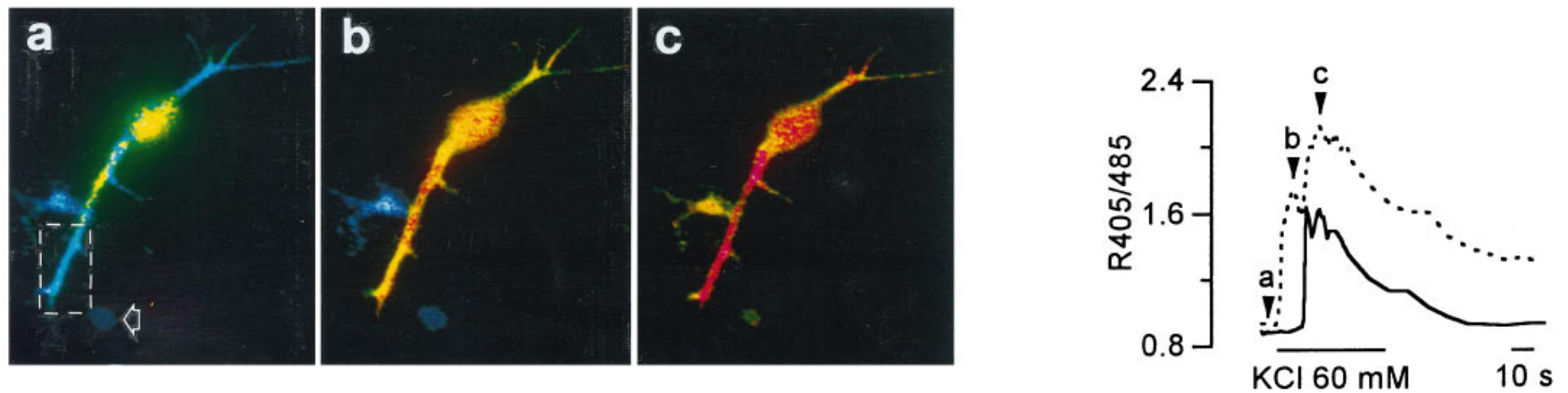

$\mathrm{F}$
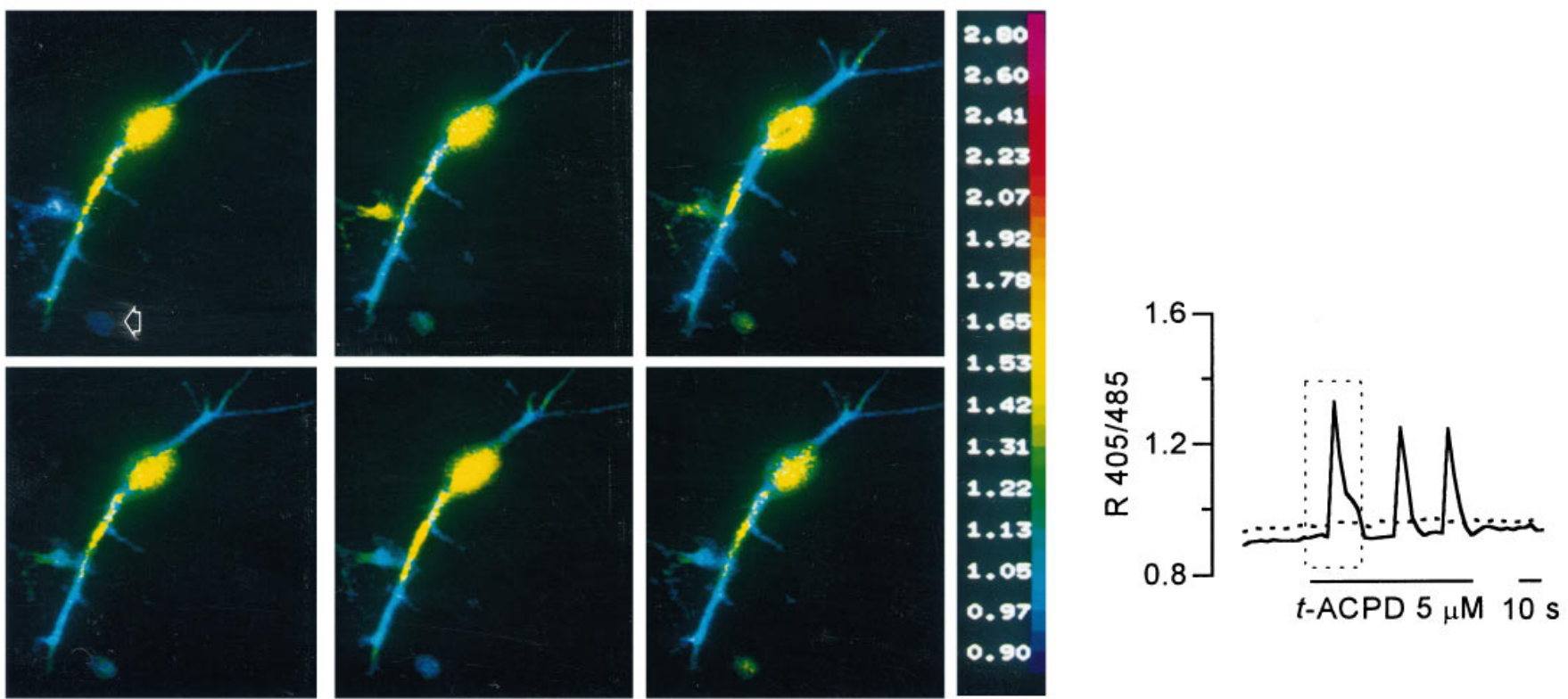

for the saturation of the signal at the center of the cell bodies (black) in the injected astrocyte and neuron. Scale bar, $10 \mu \mathrm{m} . B$, Bright field from the same region as in $A$. The indo-1-injected neuron and astrocyte are indicated by black arrows. The latter cell lies on a slightly different focus plane. $C$, Absence of action potential discharges in the astrocyte after hyperpolarizing and depolarizing current pulses of increasing amplitude and 100 msec duration. $D$, Action potential discharge in the pyramidal neuron on a depolarizing current pulse of $200 \mathrm{pA}$ and 100 msec duration. $E$, Pseudocolor images of the $\left[\mathrm{Ca}^{2+}\right]_{\mathrm{i}}$ changes after $60 \mathrm{~mm} \mathrm{KCl}$ stimulation. Letters $a-c$ in the plot refer to the images $a-c$. The laser power was set to a level that allowed us to visualize both the neuron and the less-loaded astrocyte. As a consequence, the fluorescence at $485 \mathrm{~nm}$ at the soma of the neuron reached saturation; accordingly, yellow does not correspond to the real value of the R405/485. The $\left[\mathrm{Ca}^{2+}\right]_{\mathrm{i}}$ change after both $60 \mathrm{~mm} \mathrm{KCl}$ and $5 \mu \mathrm{M} t$-ACPD was, therefore, measured from a portion of the dendrite (dashed lines box). Sampling rate, $1 \mathrm{sec}$; scale bar, $10 \mu \mathrm{m}$. $F$, Time series of pseudocolor images of the [Ca $\left.{ }^{2+}\right]_{\mathrm{i}}$ changes after $t$-ACPD stimulation. The injected astrocyte displayed periodic $\left[\mathrm{Ca}^{2+}\right]_{\mathrm{i}}$ oscillations on $t$-ACPD stimulation (right). Sampling rate, 3 sec. One of the dye-coupled astrocytes also responded to $t$-ACPD (black arrow). 
A

Figure 4. Long-term changes of the astrocyte response to $t$-ACPD. $A$, Progressive increase in the frequency of $\left[\mathrm{Ca}^{2+}\right]_{\mathrm{i}}$ oscillations on three successive stimulations with $5 \mu \mathrm{M} t$ ACPD in one astrocyte oscillating at low frequency after the first stimulation. The continuous line at the bottom of the traces indicates the application of $t$-ACPD. The time interval between stimulations was $10 \mathrm{~min}$. $B$, The frequency of $\left[\mathrm{Ca}^{2+}\right]_{\mathrm{i}}$ oscillations on three successive bath applications of $5 \mu \mathrm{M}$ $t$-ACPD did not increase in one astrocyte oscillating at high frequency during the first stimulation. Conditions and labels are as in $A$. $C$, The frequency of oscillations in each cell, as measured during the first $t$-ACPD pulse, is plotted as a function of the relative change in oscillation frequency in the second (filled symbols) and third (open symbols) with respect to the first pulse. $D$, Average frequency of oscillations after the three $t$-ACPD stimulations $(I, I I$, and $I I I)$ from all astrocytes (open bars) and from a subpopulation of astrocytes comprising cells oscillating at a frequency $\leq 1$ (striped bars); ${ }^{*} p<0.05 ;{ }^{*} p<0.001$ (paired $t$ test). The frequency of $\left[\mathrm{Ca}^{2+}\right]_{\mathrm{i}}$ oscillations in this as well as in the other figures is expressed as the number of $\left[\mathrm{Ca}^{2+}\right]_{i}$ peaks per minute.

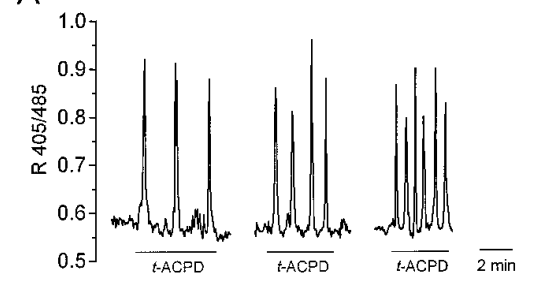

$\mathrm{C}$

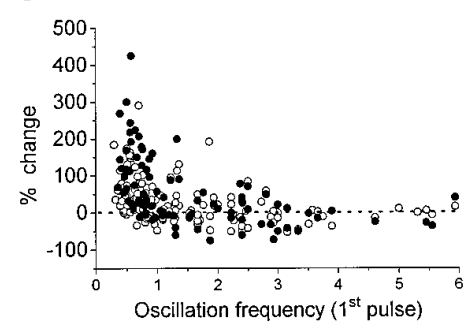

B

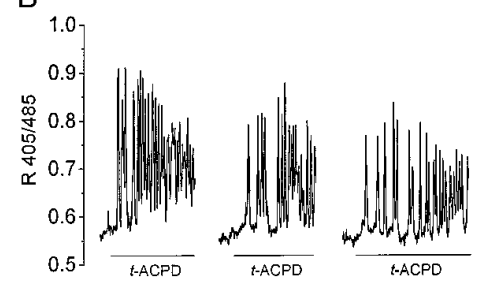

D

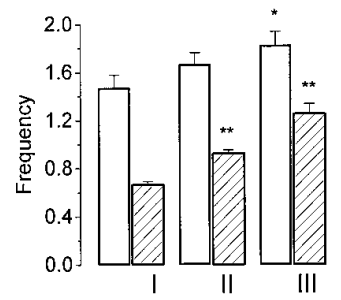

lyzed at the confocal microscope. Figure $3 A$ illustrates an astrocyte and a pyramidal neuron (closed arrows) after intracellular injection of indo-1 (bright field is shown in Fig. 3B). Neurons were identified electrophysiologically by their action potential discharges on depolarizing current pulses (Fig. $3 D$ ) and astrocytes by their absence (Fig. 3C) and highly negative resting potentials $(<75 \mathrm{mV})$. In addition, indo- 1 staining was observed not only in the patched astrocyte but also in other small cells, like those indicated in Figure $3 A$ by open arrows, indicating coupling via gap junctions. Small-sized cells were never stained with indo-1 when only neurons were injected $(n=12)$, excluding the existence of communication between these two types of cells, at least in the brain regions that were analyzed. As illustrated in the pseudocolor images of Figure $3 E a-c$, after perfusion with $60 \mathrm{~mm} \mathrm{~K}^{+}$the neuron displayed a prompt $\left[\mathrm{Ca}^{2+}\right]_{\mathrm{i}}$ increase (Fig. $3 E b$ ), whereas the response of the astrocyte appeared several seconds after that of the neuron (Fig. 3Ec). A similar response was detected in another small cell (open arrow) dye-coupled with the injected astrocyte. The kinetics of the $\left[\mathrm{Ca}^{2+}\right]_{\mathrm{i}}$ increase in the electrophysiologically classified neuron (dashed line) and astrocyte (continuous line) are reported in Figure $3 E$ (right). As previously observed in cells from slices loaded with indo-1/AM, the pyramidal neuron displayed a biphasic response to stimulation with $60 \mathrm{mM} \mathrm{K}^{+}$, and the second $\left[\mathrm{Ca}^{2+}\right]_{\mathrm{i}}$ increase occurred at the time of the $\left[\mathrm{Ca}^{2+}\right]_{\mathrm{i}}$ increase in the astrocyte. After removal of $\mathrm{KCl}$, the slice was perfused with $t$-ACPD $(5 \mu \mathrm{M})$. The sequence of images in Figure $3 F$ (left) and the kinetics of the $\left[\mathrm{Ca}^{2+}\right]_{\mathrm{i}}$ changes (Fig. $3 F$, right) demonstrate that the small cell responded to $t$-ACPD with $\left[\mathrm{Ca}^{2+}\right]_{\mathrm{i}}$ oscillations, whereas the neuron was unresponsive. Identical results were obtained from two additional experiments.

In conclusion, on the basis of these observations, the delayed increase in the response to $60 \mathrm{mM} \mathrm{K}^{+}$reasonably can be used as a criterion to distinguish astrocytes from neurons in situ. In the various experiments that will be described below, at the end of each recording session astrocytes and neurons were identified according to the different kinetics of their response to stimulation with $60 \mathrm{~mm} \mathrm{~K}^{+}$. It cannot be excluded that other non-neuronal cells such as oligodendrocytes might respond to the various stimuli with a pattern similar to that of astrocytes, but their number in the brain regions we analyzed is known to be much lower than that of the astrocytes.

\section{Repetitive activation of the mGluR induces long-term changes in $\left[\mathrm{Ca}^{2+}\right]_{i}$ oscillations in astrocytes}

We previously reported that astrocytes from the visual cortex in culture displayed a long-term modification of their response, i.e., an increased frequency of $\left[\mathrm{Ca}^{2+}\right]_{i}$ oscillations, on repetitive stimulation with L-glutamate (Pasti et al., 1995). We thus investigated whether repetitive stimulation with $t$-ACPD can induce a similar potentiation in the response of astrocytes from acute brain slices. Oscillations in neuronal cells will be considered separately. Figure $4 A$ shows the oscillatory response from one astrocyte on three successive $5 \mu \mathrm{M} t$-ACPD stimulations applied with a time interval of $10 \mathrm{~min}$. The second stimulation induced $\left[\mathrm{Ca}^{2+}\right]_{i}$ oscillations of increased frequency, although their amplitude and shape did not change significantly (Fig. 4A). A third stimulation resulted in a further increase in oscillation frequency. The potentiation of the response was observed mainly in astrocytes displaying a low frequency of oscillations during the first challenge with $t$-ACPD, as in the case reported in Figure $4 A$, whereas those oscillating initially at high frequency (Fig. $4 B$ ) were, in general, not potentiated. Results are summarized in Figure $4 C$, which reports the relative change in oscillation frequency occurring in each cell on the second (filled symbols) and third (open symbols) t-ACPD stimulations as a function of the oscillation frequency on the first $t$-ACPD stimulation. The average increase in oscillation frequency on repetitive stimulation obtained from a subpopulation of cells comprising astrocytes oscillating initially at a frequency $\leq 1$ was more pronounced than that obtained from the whole population of cells (Fig. 4D, Table 1). Similar results were obtained from visual cortical astrocytes (Table 1).

In contrast to the results obtained in culture, in calcium-free medium astrocytes in situ failed to respond to $t$-ACPD with an oscillatory pattern and displayed, in most cases, a single $\left[\mathrm{Ca}^{2+}\right]_{\mathrm{i}}$ rise (data not shown). Only a few cells (5 of 30) exhibited two or three $\left[\mathrm{Ca}^{2+}\right]_{\mathrm{i}}$ transients under these conditions. The subsequent addition in the perfusate of $2 \mathrm{mM} \mathrm{Ca}^{2+}$ resulted in an immediate increase in the $\left[\mathrm{Ca}^{2+}\right]_{\mathrm{i}}$ that recovered to basal levels in a relatively short time. At this extracellular $\mathrm{Ca}^{2+}$ concentration the normal response to $t$-ACPD stimulation was restored $(n=13)$. 
Table 1. Frequency of $\left[\mathrm{Ca}^{2+}\right]$ oscillations and its relative change in astrocytes after three consecutive $t$-ACPD applications

\begin{tabular}{|c|c|c|c|c|}
\hline & $\begin{array}{l}\text { Number of } \\
\text { astrocytes }\end{array}$ & $\begin{array}{l}\text { Oscillation frequency } \\
\text { mean } \pm \mathrm{SE} \\
\mathrm{I} \text { pulse }\end{array}$ & $\begin{array}{l}\text { Change in frequency }(\%) \\
\text { mean } \pm \mathrm{SE} \\
\text { II pulse }\end{array}$ & $\begin{array}{l}\text { Change in frequency }(\%) \\
\text { mean } \pm \mathrm{SE} \\
\text { III pulse }\end{array}$ \\
\hline CA1 & $132(20)$ & $1.55 \pm 0.11$ & $+28.4 \pm 5.6$ & $+44.7 \pm 8.7$ \\
\hline CA1 subpopulation & $57(20)$ & $0.66 \pm 0.02$ & $+46.2 \pm 7.9$ & $+98.8 \pm 13.7$ \\
\hline Visual cortex & $15(4)$ & $1.05 \pm 0.13$ & $+47.4 \pm 13.1$ & $+53 \pm 7.41$ \\
\hline CA1 (3 hr interval) & $19(2)$ & $0.80 \pm 0.11$ & $+62.7 \pm 13.4$ & ND \\
\hline
\end{tabular}

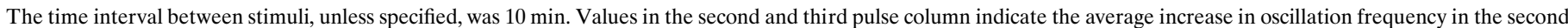

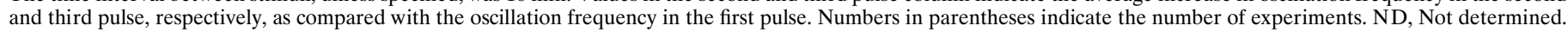

The change in oscillation frequency is a relatively long-lasting phenomenon. In fact, we observed a significant increase in oscillation frequency when the second $t$-ACPD stimulation was applied after a time interval of $3 \mathrm{hr}$ (see Table 1).

$t$-ACPD is known to activate all the mGluR subtypes, although with different affinity. To identify the mGluR subtype that mediates $\left[\mathrm{Ca}^{2+}\right]_{i}$ oscillations in astrocytes, we used several known blockers of group $1 \mathrm{mGluRs}$. The competitive antagonist 4CPG (10-500 $\mu \mathrm{M}$; Watkins and Collingridge, 1994) did not block $t$-ACPD-induced oscillations in a total of 30 astrocytes from the hippocampus and 11 from the visual cortex. The mGluR1/5 antagonist AIDA (50-200 $\mu \mathrm{M} ; n=14$, two experiments; Pellicciari et al., 1995), as well as the noncompetitive antagonist L-AP3 (30 $\mu \mathrm{M} ; n=11$, two experiments), was also ineffective. In contrast, the nonspecific mGluR antagonist MCPG at $1 \mathrm{~mm}$ concentration blocked $t$-ACPD-induced $\left[\mathrm{Ca}^{2+}\right]_{\mathrm{i}}$ increases.

\section{Neuronal stimulation induces $\left[\mathrm{Ca}^{2+}\right]_{\mathrm{i}}$ oscillations in astrocytes}

By applying current pulses to afferent projections through a bipolar tungsten electrode, we next investigated whether stimulation of neuronal afferents could trigger $\left[\mathrm{Ca}^{2+}\right]_{\mathrm{i}}$ oscillations in astrocytes. The sequence of images in Figure $5 A$ corresponds to the portion of the trace highlighted by the dashed lines box in Figure $5 B$ and illustrates the somatic $\left[\mathrm{Ca}^{2+}\right]_{\mathrm{i}}$ transients of a pyramidal neuron (cell 1) in response to stimulation at $0.16 \mathrm{~Hz}$ of Schaffer collaterals. Between stimuli, $\left[\mathrm{Ca}^{2+}\right]_{\mathrm{i}}$ recovered to baseline levels (see also top trace in Fig. $5 B$ ). A $\left[\mathrm{Ca}^{2+}\right]_{\mathrm{i}}$ rise out of synchrony with the stimulus was observed in cell 2 that was identified retrospectively as an astrocyte. On continuous neuronal stimulation this cell displayed repetitive transients with a relatively regular periodicity (Fig. $5 B$ ). The $\left[\mathrm{Ca}^{2+}\right]_{\mathrm{i}}$ increase in astrocytes occurred, in general, with a delay of $10-16 \mathrm{sec}$ with respect to that of adjacent neurons, although a delay of $<2 \mathrm{sec}$ was, in some cases, observed when the train of stimuli was applied at a frequency of $1 \mathrm{~Hz}$. In all cases, the $\left[\mathrm{Ca}^{2+}\right]_{\mathrm{i}}$ oscillations in the astrocytes were clearly out of synchrony with respect to the timing of the electrical stimulation. Interestingly, $\left[\mathrm{Ca}^{2+}\right]_{i}$ oscillations with a frequency higher than that at the soma were observed at the level of the astrocyte process labeled 3 in Figure $5 A$ (see bottom trace in Fig. $5 B$ ). Figure 5, $C$ and $D$, illustrates an additional example. The sequence of images (Fig. $5 C$ ) shows that, on stimulation of Schaffer collaterals at $0.16 \mathrm{~Hz}$, the $\left[\mathrm{Ca}^{2+}\right]_{\mathrm{i}}$ increase initially was restricted to the process only (arrow), whereas the second $\left[\mathrm{Ca}^{2+}\right]_{\mathrm{i}}$ increase spread through the whole cell body (see also inset of Fig. $5 D)$. The kinetics of the $\left[\mathrm{Ca}^{2+}\right]_{\mathrm{i}}$ changes from the process and the soma are compared in Figure $5 D$ (the trace within the dashed lines box corresponds to the sequence of images in $C$ ). Oscillations triggered by stimulation of afferent fibers were observed in a low number of astrocytes corresponding to $\sim 15 \%$ of indo-1-loaded astrocytes.

These results suggest that glutamate released by synaptic terminals is responsible for the $\left[\mathrm{Ca}^{2+}\right]_{\mathrm{i}}$ increase in astrocytes. However, the stimulation of presynaptic fibers can trigger action potential discharges in target neurons and results in a secondary release of the neurotransmitter. The $\left[\mathrm{Ca}^{2+}\right]_{\mathrm{i}}$ change in astrocytes might, therefore, originate also from glutamate released at synapses that belong to intrinsic connections among target neurons. To investigate this point, we blocked the activation of postsynaptic neurons by perfusing slices with the AMPAR antagonist NBQX $(50 \mu \mathrm{M})$ and the NMDAR open channel blocker MK801 $(50 \mu \mathrm{M}$; Watkins et al., 1990). Under these conditions the electrical stimulus failed to produce any $\left[\mathrm{Ca}^{2+}\right]_{\mathrm{i}}$ change in neurons that were responsive before the application of the blockers, whereas astrocytes were still responsive with a pattern of oscillations similar to that observed in the absence of glutamate receptor antagonists (Fig. 5B). On the contrary, perfusion with the $\mathrm{Na}^{+}$channel blocker tetrodotoxin (TTX; $5 \mu \mathrm{M}$ ) abolished the response from both types of cells (15 neurons and 7 astrocytes in CA1 region from two hippocampal slices; 10 neurons and 4 astrocytes from two visual cortical slices). The perfusion for 15 min with the mGluR antagonist MCPG (1 $\mathrm{mm}$ ) abolished the astrocyte response to electrical stimulation of afferents, whereas that from neurons was unchanged (14 neurons and 8 astrocytes from four hippocampal slices).

\section{Neuronal stimulation modulates the frequency of oscillations in astrocytes}

Having demonstrated that neuronal activity can trigger $\left[\mathrm{Ca}^{2+}\right]_{i}$ oscillations in astrocytes from both visual cortex and hippocampus, we next investigated whether the frequency of oscillations could change according to the firing rates of neuronal afferents. We analyzed the oscillatory response of astrocytes after a train of stimuli applied first at low frequency $(0.1-0.2 \mathrm{~Hz})$ and low intensity (50-100 pA) and then at either increased frequency (0.3-1 $\mathrm{Hz}$ ) or higher intensity (200-500 pA). Figure 6 shows that an increase in either the frequency $(A)$ or intensity $(B)$ of the stimulus resulted in a clear increase in the frequency of $\left[\mathrm{Ca}^{2+}\right]_{\mathrm{i}}$ oscillations in astrocytes. The mean frequency before and after the change in the stimulus is reported in Figure 6, $A$ and $B$ (right). When the frequency of the stimulus was increased, the average frequency of oscillations $( \pm \mathrm{SE}$ ) changed from $1.41 \pm 0.23$ to $2.16 \pm 0.24 \mathrm{peaks} / \mathrm{min}$. When the percentage of increase in oscillation frequency in the second with respect to the first stimulation from each individual astrocyte was taken into account, the average increase ( $\pm \mathrm{SE}$ ) corresponded to $115 \pm 44.1 \%$. A similar increase was obtained when the stimulus was applied at higher intensity (mean $\pm \mathrm{SE} ; 106 \pm 27.5 \%, n=20$ ). It is noteworthy that changes in the pattern of the electrical stimulus induced either an 

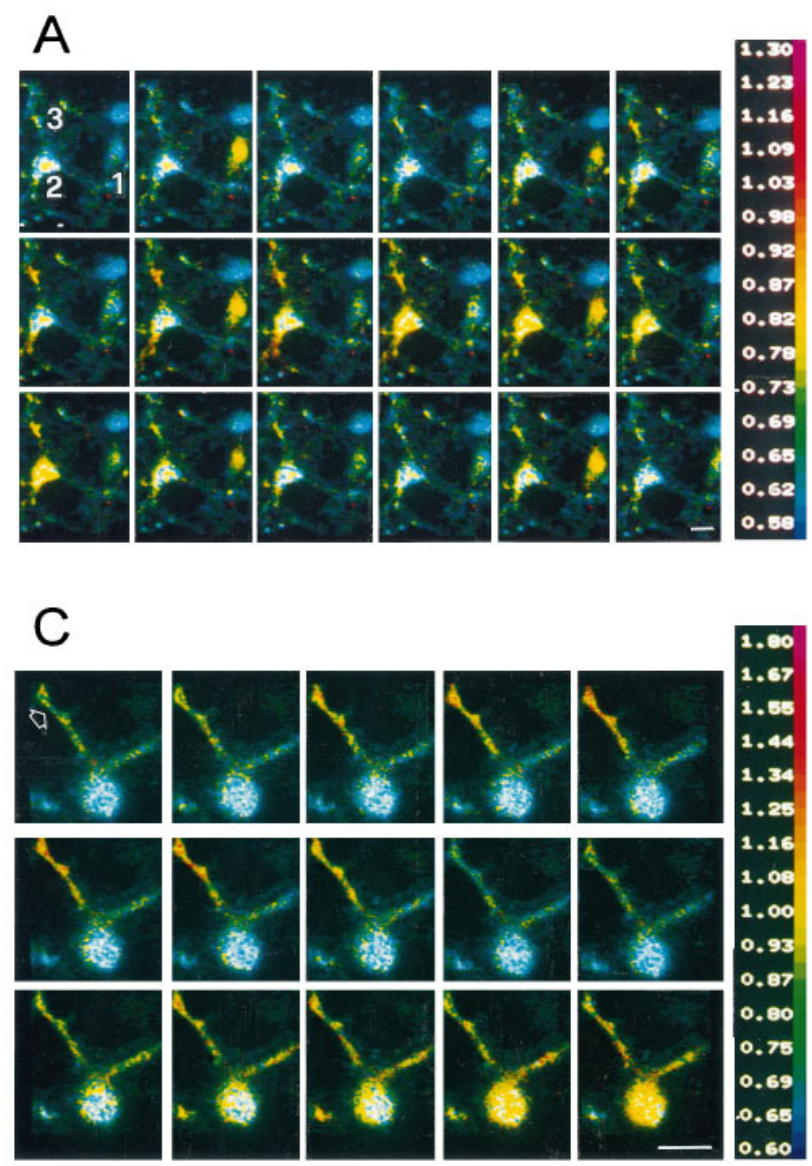

B

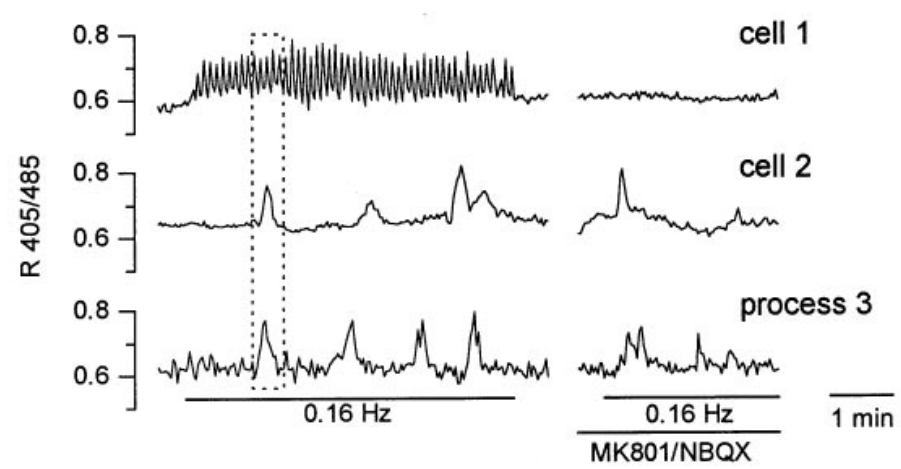

D

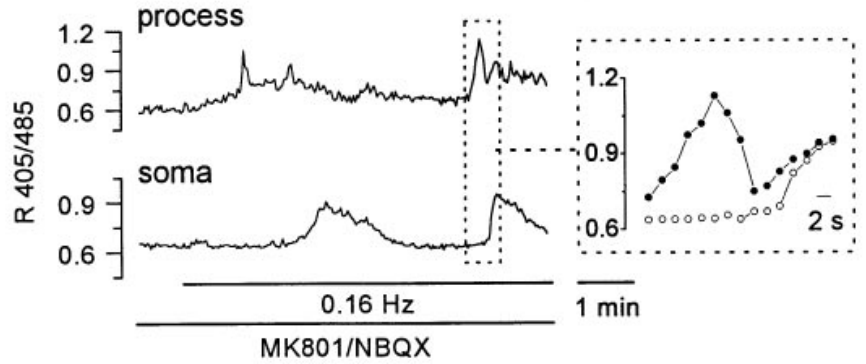

Figure 5. Neuronal activity-dependent $\left[\mathrm{Ca}^{2+}\right]_{\mathrm{i}}$ oscillations in astrocytes. $A$, Time series of pseudocolor images illustrating the $\left[\mathrm{Ca}{ }^{2+}\right]_{\mathrm{i}}$ changes in one pyramidal neuron (labeled 1) and one adjacent astrocyte (labeled 2) from CA1 hippocampal region of a 8-d-old rat after neuronal stimulation at 0.16 $\mathrm{Hz}$, i.e., a series of six pulses at $30 \mathrm{~Hz}$ applied every $6 \mathrm{sec}$. Label 3 indicates one of the astrocyte processes. The sequence of images (time interval, 2 $\mathrm{sec})$ corresponds to the portion of the traces shown in $B$ and is highlighted by the dashed lines box. Because the pyramidal neuron and the astrocyte were localized at a different depth and the plane of focus was set to visualize the astrocyte, the neuron looks smaller than the astrocyte. The real mean diameter of the neuron was $16.9 \mu \mathrm{m}$, whereas that of the astrocyte was $10 \mu \mathrm{m}$. Scale bar, $10 \mu \mathrm{m}$. $B$, Kinetics of the [Ca $\left.{ }^{2+}\right]_{\mathrm{i}}$ changes in the cells and the process shown in $A$ after two successive episodes of neuronal stimulation applied with 5 min intervals. The second episode of stimulation was performed in the presence of MK801 and NBQX, both at $50 \mu \mathrm{M}$. $C$, Time series of pseudocolor images illustrating the $\left[\mathrm{Ca}^{2+}\right]_{\mathrm{i}}$ changes in an astrocyte as measured at the level of one process ( filled arrow) and the cell body after neuronal stimulation. The sequence of images (time interval, 2 sec) corresponds to the portion of the trace highlighted by the dashed lines box in $D$. Scale bar, $10 \mu \mathrm{m}$. $D$, Kinetics of the $\left[\mathrm{Ca}^{2+}\right]_{\mathrm{i}}$ oscillations in the process and the soma of the astrocyte shown in $C$ during neuronal stimulation at $0.16 \mathrm{~Hz}$. In the inset, the sequence of points representing the R405/485 values at the process ( filled symbols) and the soma (open symbols) corresponds to the sequence of images in $C$.

increased amplitude of the $\left[\mathrm{Ca}^{2+}\right]_{\mathrm{i}}$ rise in neurons that were already responsive, as in the case of the two neurons in $A$ and $B$, or the appearance of $\left[\mathrm{Ca}^{2+}\right]_{\mathrm{i}}$ increased in neurons and astrocytes that were initially unresponsive (data not shown), suggesting the recruitment of additional presynaptic inputs.

In the experiment presented in Figure 4, we showed that successive $t$-ACPD stimulations resulted in an increase in the frequency of $\left[\mathrm{Ca}^{2+}\right]_{\mathrm{i}}$ oscillations in astrocytes. The question then arises as to whether a similar form of potentiation in astrocytes can be elicited by repetitive stimulation of afferent fibers. Figure $6 C$ shows the response from a single astrocyte for which the frequency of $\left[\mathrm{Ca}^{2+}\right]_{\mathrm{i}}$ oscillations changed from 1.0 at the first to 2.1 at the second series of pulses. Similar to what was observed with repetitive $t$-ACPD stimulation, the potentiation of the response was observed mainly in cells having a low frequency of oscillations at the first pulse (Fig. 6D), although the average increase in oscillation frequency (65.4 \pm $18.3 \%$; Fig. $6 D$, right) was more pronounced than that observed on two successive $t$-ACPD applications (see Table 1). The higher efficacy of neuronal stimulation in inducing the potentiation of the astrocyte response was investigated further. The experimental protocol was as follows: after the first and before the second $t$-ACPD stimulation, we applied a series of $0.5-1$ $\mathrm{Hz}$ stimuli to $\mathrm{CA} 1$ region afferent projections. As discussed above, only a percentage of the astrocytes displayed oscillations after neuronal stimulation. We thus had the ability to compare in the same slice the increase in oscillations frequency that follows the second $t$-ACPD stimulation in two astrocyte populations: the first composed of astrocytes that displayed oscillations on neuronal stimulation between the two successive $t$-ACPD applications and the second composed of astrocytes that were not responsive to neuronal stimulation. Figure $6 E$ reports the relative change in frequency in each astrocyte (left) and the mean values from the two subpopulations (right). The increase in the frequency of $\left[\mathrm{Ca}^{2+}\right]_{\mathrm{i}}$ oscillations after the second $t$-ACPD application was higher in those astrocytes that showed oscillations on neuronal stimulation (Fig. 6E, closed symbols and bars) with respect to that of astrocytes that did not 
A

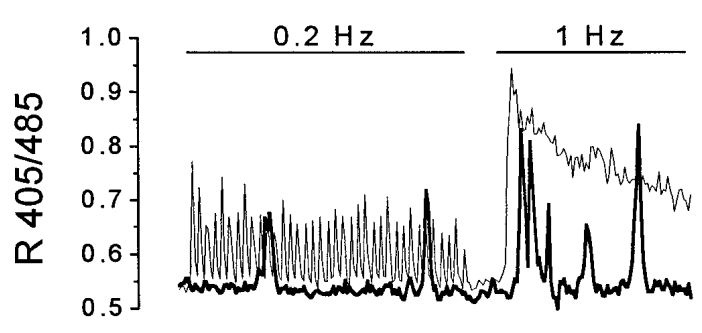

$\mathrm{B}$

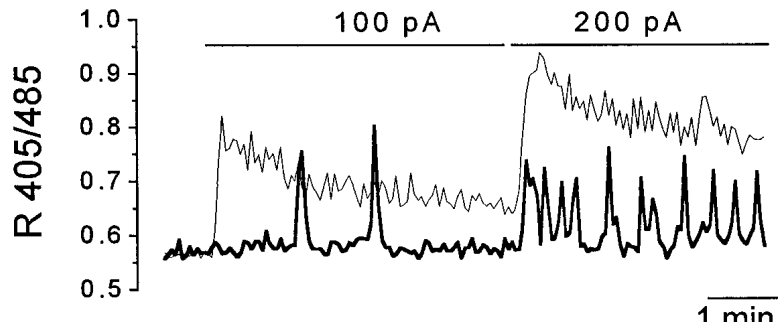

C

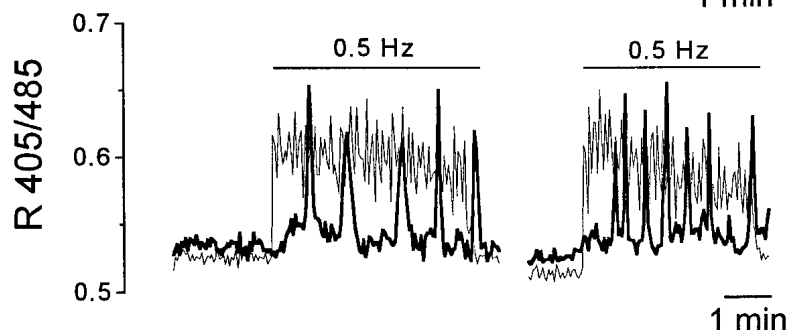

$\mathrm{D}$

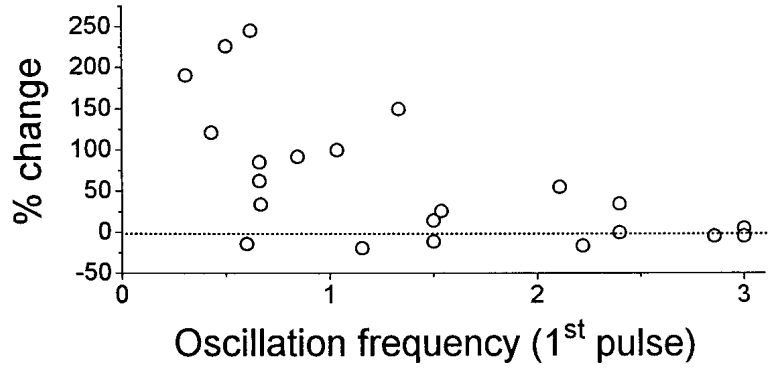

$E$

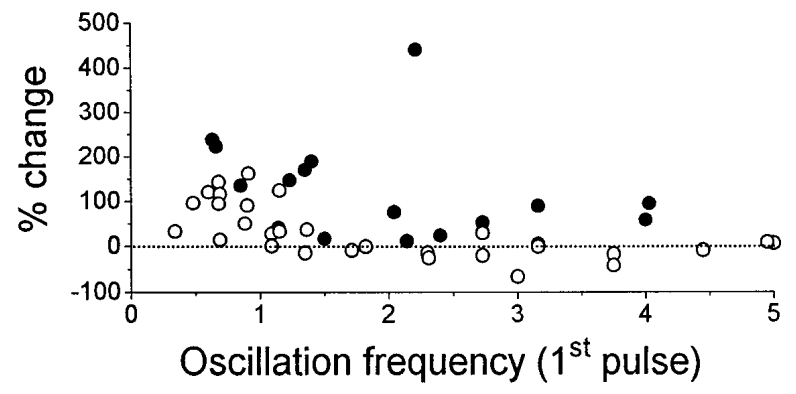

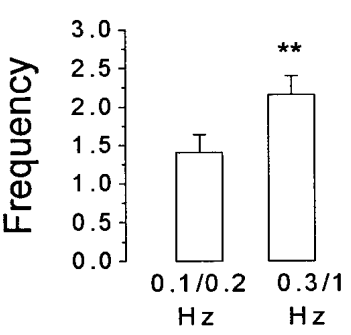

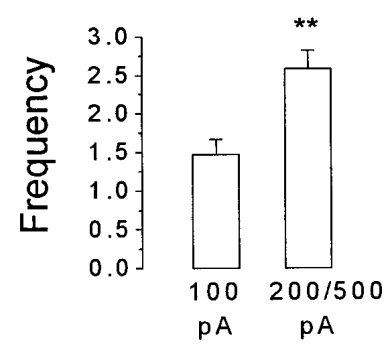

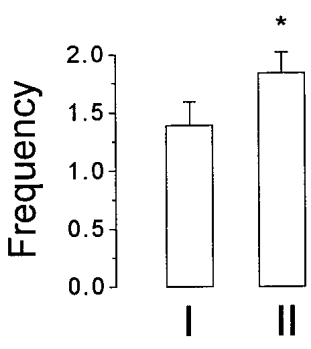

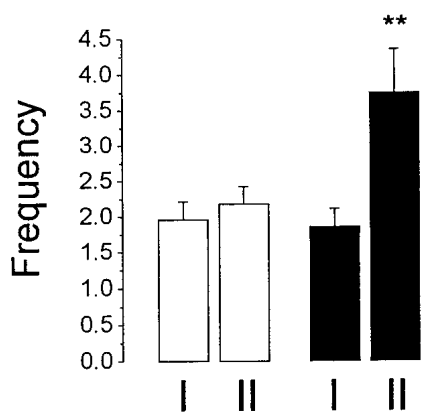

Figure 6. Neuronal activity-dependent modulation of $\left[\mathrm{Ca}^{2+}\right]_{\mathrm{i}}$ oscillation frequency in astrocytes. $A$, $\left[\mathrm{Ca}^{2+}\right]_{\mathrm{i}}$ oscillations in one astrocyte $($ thick line) after neuronal stimulation. The frequency of $\left[\mathrm{Ca}^{2+}\right]_{\mathrm{i}}$ oscillations rapidly increased after the shift in the frequency of neuronal stimulation from 0.2 to $1 \mathrm{~Hz}$. The response of an adjacent neuron to each pulse is reported also (thin line). The bar histogram reports the average oscillation frequency from a data base of 10 astrocytes in the first (stimulus frequency range, $0.1-0.2 \mathrm{~Hz}$ ) and second (stimulus frequency range, $0.3-1 \mathrm{~Hz}$ ) phase of stimulation; ${ }^{* *} p<0.001 . B,\left[\mathrm{Ca}^{2+}\right]_{\mathrm{i}}$ oscillations in one astrocyte (thick line) after neuronal stimulation at $1 \mathrm{~Hz}$. The frequency of $\left[\mathrm{Ca}^{2+}\right]_{\mathrm{i}}$ oscillations rapidly increased after the shift in the intensity of the stimulus from 100 to $200 \mathrm{pA}$. The increase in the $\left[\mathrm{Ca}^{2+}\right]_{\mathrm{i}}$ from an adjacent neuron is reported also (thin line). The bar histogram reports the average oscillation frequency from a data base of 20 astrocytes in the first and second phase of stimulation. In this second phase the frequency of the stimulus was increased from the initial $100 \mathrm{pA}$ to a minimum of $200 \mathrm{pA}$ and a maximum of $500 \mathrm{pA}$ in the various experiments; ** $<<$ 0.001 . $C$, The frequency of $\left[\mathrm{Ca}^{2+}\right]_{i}$ oscillations that follows a first episode of neuronal stimulation increased $(1.05 \mathrm{vs} 2.17$ peaks/min) after a second episode of stimulation at unchanged intensity $(100 \mathrm{pA})$ and frequency $(0.5 \mathrm{~Hz})$ applied after a time interval of $10 \mathrm{~min} . D$, The frequency of $\left[\mathrm{Ca}^{2+}\right]_{\mathrm{i}}$ oscillations in each cell, as measured in the first episode of neuronal stimulation, is plotted as a function of its relative change in the second episode of stimulation. On the right, the bar histogram summarizes data at the first $(I)$ and second (II) stimulation from a total of 22 astrocytes; * $p<0.05$. $E$, Relative change in the frequency of $\left[\mathrm{Ca}^{2+}\right]_{\mathrm{i}}$ oscillations in the second with respect to the first $t$-ACPD stimulation in astrocytes that displayed $($ filled symbols and bars) or did not display (open symbols and bars) $\left[\mathrm{Ca}^{2+}\right]_{\mathrm{i}}$ oscillations during an episode of neuronal stimulation applied between the two $t$-ACPD stimulations. The bar histogram reports the average oscillation frequency in the two astrocyte populations; ${ }^{* *} p<0.001$. 
respond to this latter challenge (open symbols and bars). It is noteworthy that the average increase at the second $t$-ACPD application in astrocytes responsive to neuronal stimulation was higher than that observed after three successive $t$-ACPD applications (114\% vs $44.7 \%$; Table 1$)$.

\section{$\left[\mathrm{Ca}^{2+}\right]_{\mathrm{i}}$ oscillations in astrocytes are followed by $\left[\mathrm{Ca}^{2+}\right]_{i}$ oscillations in neurons}

Besides the effects on astrocytes, $t$-ACPD induced in a number of CA1 pyramidal neurons either a single $\left[\mathrm{Ca}^{2+}\right]_{\mathrm{i}}$ transient or $\left[\mathrm{Ca}^{2+}\right]_{\mathrm{i}}$ oscillations. These $\left[\mathrm{Ca}^{2+}\right]_{\mathrm{i}}$ changes could be attributable to (1) direct stimulation of neuronal mGluRs (Stratton et al., 1990) and (2) $t$-ACPD-induced release of glutamate from astrocytes with activation of neuronal ionotropic glutamate receptors (iGluR), i.e., AMPA and NMDARs. Indeed, cultured astrocytes have been reported to release glutamate and excite adjacent neurons (Parpura et al., 1994a; Jeftinija et al., 1996). Figure 7, $A$ and $B$, shows a typical oscillatory response induced by $10 \mu \mathrm{M}$ $t$-ACPD in one neuron $(A)$ and one adjacent astrocyte $(B)$. On washout of the antagonist, the $\left[\mathrm{Ca}^{2+}\right]_{\mathrm{i}}$ returned to basal levels in both cell types. A second challenge with $t$-ACPD $(10 \mu \mathrm{M})$ was applied in the presence of NBQX and D-AP5 (both at $50 \mu \mathrm{M}$ ), specific antagonists of AMPAR and NMDARs, respectively. Under these conditions, in this as well as in a number of other neurons (14 of 49), the response to $t$-ACPD was inhibited completely but recovered on washout of the antagonists (Fig. 7A), whereas the astrocyte response was not changed significantly (Fig. $7 B)$. In the remaining 35 neurons, the response to the second $t$-ACPD stimulation, performed in the presence of NBQX and D-AP5, either was decreased significantly in amplitude, as in the case reported in Figure $7 C$, or was unchanged. As a mean, the amplitude of the $\left[\mathrm{Ca}^{2+}\right]_{\mathrm{i}}$ elevation induced in neurons by $10 \mu \mathrm{M}$ $t$-ACPD applied in the presence of NBQX/D-AP5 was reduced significantly (Fig. 7D). The relative change in the amplitude of the $\left[\mathrm{Ca}^{2+}\right]_{\mathrm{i}}$ increase in each neuron at the second (in the presence of the AMPAR and NMDAR blockers) with respect to the first $t$-ACPD stimulation is reported in Figure $7 D$. It is noteworthy that no reductions of the response after two successive $t$-ACPD stimulations were observed in control neurons $(n=32$; Fig. $7 D)$. These results indicate that $\left[\mathrm{Ca}^{2+}\right]_{\mathrm{i}}$ elevations in neurons can be elicited, partially or totally, by glutamate released in response to the $t$-ACPD challenge. To clarify whether glutamate released after $t$-ACPD stimulation derived from afferent fibers, neurons, or astrocytes, we incubated the slice with TeNT $(100 \mu \mathrm{g} / \mathrm{ml})$. TeNT is known to be a highly specific blocker of neurotransmitter secretion in neurons (Calabresi et al., 1989; Schiavo et al., 1992). Its action is exerted on the vesicle-associated membrane protein VAMP/synaptobrevin (Schiavo et al., 1992), one of the components of the neuroexocytosis apparatus, after cell internalization probably via the recycling of synaptic vesicles (Matteoli et al., 1996). Although VAMP/synaptobrevin is expressed in many cell types besides neurons, the lack of TeNT effects on other cell types probably depends on the absence of a receptor for the neurotoxin (Parpura et al., 1994b; Rossetto et al., 1996). By recording EPSCs from CA1 neurons in response to stimulation of the Schaffer collaterals before and after perfusion of the slice with TeNT $(100 \mu \mathrm{g} / \mathrm{ml})$, we obtained evidence for the inhibitory effects of TeNT on synaptic transmission. As shown in Figure $7 E$, the EPSC first was reduced in amplitude and then abolished after 20 min of TeNT treatment. Despite changing the position of the stimulating electrode and increasing the stimulus intensity, we obtained no response from this and three other neurons of the same slice, as well as from neurons of an additional slice, tested after $40 \mathrm{~min}$ of incubation with TeNT. In toxin-treated slices the effects of $t$-ACPD on both neurons and astrocytes was unchanged, as compared with controls: it stimulated $\left[\mathrm{Ca}^{2+}\right]_{i}$ oscillations in astrocytes and $\left[\mathrm{Ca}^{2+}\right]_{\mathrm{i}}$ elevations in neurons. In 6 of $35 t$-ACPDresponsive neurons, the response was inhibited completely by NBQX/D-AP5 application, whereas in the remaining 29 neurons the amplitude was either reduced significantly or unchanged. As a mean, the reduction of the response of neurons to $t$-ACPD by NBQX and D-AP5 in toxin-treated slices was not significantly different as compared with that obtained from neurons in toxinuntreated slices (Fig. 7D, right). The relative change in the amplitude of the $\left[\mathrm{Ca}^{2+}\right]_{\mathrm{i}}$ increase in each neuron after the second with respect to the first $t$-ACPD stimulation also is reported in Figure $7 D$ (right).

The inhibitory effect of TeNT on neurotransmitter exocytosis was confirmed in each slice used at the confocal microscope by the following experimental observations (data not shown in figures): (1) electrical stimulation of Schaffer collaterals failed to produce $\left[\mathrm{Ca}^{2+}\right]_{\mathrm{i}}$ increases in both neurons and astrocytes; (2) small cells, i.e., presumed astrocytes, did not display any $\left[\mathrm{Ca}^{2+}\right]_{i}$ increase after $60 \mathrm{~mm} \mathrm{~K}{ }^{+}$stimulation; and (3) pyramidal neurons still responded to $\mathrm{K}^{+}$-induced depolarization with an early $\left[\mathrm{Ca}^{2+}\right]_{\mathrm{i}}$ increase, but their response did not display the biphasic pattern observed in controls (see Figs. $1 C, 3 E$ ) and recovered to $\left[\mathrm{Ca}^{2+}\right]_{\mathrm{i}}$ basal levels much faster than in neurons from toxin-untreated slices.

In the great majority of neurons (16 of 20) from untreated and TeNT-treated slices for which the $\left[\mathrm{Ca}^{2+}\right]_{i}$ increase was entirely attributable to the $t$-ACPD-induced release of glutamate, the pattern of the response was clearly oscillatory (see, for example, Fig. 7A).

When a second $t$-ACPD challenge was applied in the presence of the mGluR antagonist MCPG $(1 \mathrm{mM})$, the $\left[\mathrm{Ca}^{2+}\right]_{\mathrm{i}}$ elevations observed after the first $t$-ACPD stimulation were abolished in all responsive astrocytes $(n=8)$ and neurons $(n=12)$.

\section{DISCUSSION}

\section{Long-term changes in oscillation frequency mediated by $t$-ACPD}

We previously reported that successive stimulations of the $\mathrm{mGluR}$ in cultured astrocytes induced a long-lasting increase in $\left[\mathrm{Ca}^{2+}\right]_{\mathrm{i}}$ oscillation frequency (Pasti et al., 1995). Here we dem-

Figure 7. Astrocyte oscillations mediate repetitive $\left[\mathrm{Ca}^{2+}\right]_{\mathrm{i}}$ increases in neurons. $A,\left[\mathrm{Ca}^{2+}\right]_{\mathrm{i}}$ repetitive increases in one pyramidal hippocampal neuron after three consecutive stimulations with $10 \mu \mathrm{M} t$-ACPD. The response to $t$-ACPD was abolished by NBQX/D-AP5. Before the second $t$-ACPD application, the slice was perfused for $10 \mathrm{~min}$ with NBQX and D-AP5, both at $50 \mu \mathrm{M}$. Before the third $t$-ACPD stimulation, the slice was perfused with normal saline for $20 \mathrm{~min} . B,\left[\mathrm{Ca}^{2+}\right]_{\mathrm{i}}$ oscillations in one astrocyte adjacent to the neuron in $A$ after the three $t$-ACPD stimulations. $C$, Reduction by NBQX and D-AP5, both at $50 \mu \mathrm{M}$, in the amplitude of the $t$-ACPD-induced $\left[\mathrm{Ca}^{2+}\right]_{\mathrm{i}}$ increase after the second episode of stimulation from a hippocampal pyramidal neuron and its recovery in the third $t$-ACPD stimulation performed in the absence of the iGluR blockers after a time interval of 20 min. $D$, Relative change in the amplitude of the $\left[\mathrm{Ca}^{2+}\right]_{\mathrm{i}}$ increase in each neuron after the second $t$-ACPD stimulation performed in the absence (control) or presence of $N B Q X \mid A P 5$, as compared with the first $t$-ACPD stimulation. Filled symbols represent the values of the mean \pm SE. (Figure legend continues) 

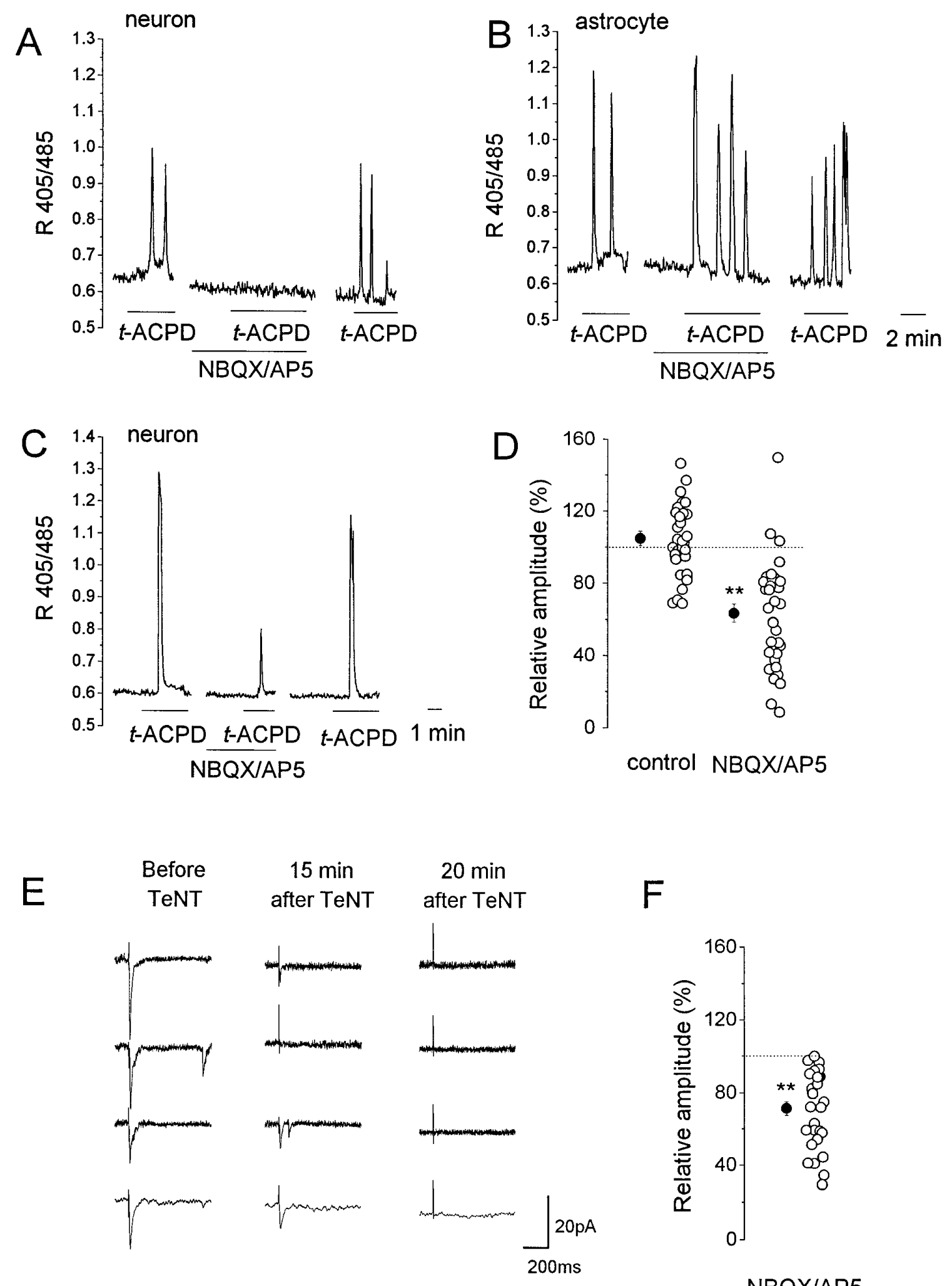

\section{NBQXIAP5}

The mean change in the response from NBQX/D-AP5 neurons was significantly different from that from control neurons; ** $p<0.0001 ; t$ test. $E$, Whole-cell recordings of EPSCs evoked on a CA1 pyramidal neuron by stimulation of Schaffer collaterals at $0.2 \mathrm{~Hz}$. Three consecutive EPSCs and the average trace from eight consecutive EPSCs (bottom traces) before and after the TeNT application are shown. Despite increasing the intensity of the stimulus (note the increased amplitude of the stimulus artifact), we recorded no EPSCs 20 min after TeNT. $F$, Relative change in the amplitude of the $\left[\mathrm{Ca}^{2+}\right]_{\mathrm{i}}$ increase after the second $t$-ACPD stimulation, as compared with the first $t$-ACPD stimulation, in each neuron from slices incubated for $40-60$ min with TeNT. The second $t$-ACPD stimulation was performed in the presence of NBQX/D-AP5, both at $50 \mu \mathrm{M}$. The mean change in the response from these neurons was significantly different with respect to that from control neurons $\left({ }^{* *} p<0.0001 ; t\right.$ test), but not with respect to that from NBQX/D-AP5 neurons from slices not treated with TeNT. Symbols are as in $D$. 
onstrate that repetitive activations of mGluRs by $t$-ACPD induce a similar potentiation in the $\left[\mathrm{Ca}^{2+}\right]_{\mathrm{i}}$ response of astrocytes in acute brain slices from both CA1 hippocampal region and visual cortex. The potentiation was induced rapidly and was relatively long-lasting. In contrast to the results obtained in cultured astrocytes (Pasti et al., 1995), in the absence of extracellular $\mathrm{Ca}^{2+}$, astrocytes either failed to oscillate or displayed rapidly fading oscillations. The effects of $t$-ACPD on astrocytes probably are mediated by the mGluR5 subtype (Romano et al., 1995). Antagonists of group $1 \mathrm{mGluRs}$ with a preference specificity for mGluR1, failed, however, to affect $t$-ACPD-induced oscillations, whereas MCPG, a nonspecific mGluR antagonist, blocked the response. The mGluR subtype responsible for $\left[\mathrm{Ca}^{2+}\right]_{i}$ oscillations thus remains to be established.

\section{Modulation of the astrocyte response by neuronal activity}

One of the most striking observations of this study is that astrocytes are extremely sensitive to synaptic activity. Indeed, the pattern of their $\left[\mathrm{Ca}^{2+}\right]_{i}$ oscillations in response to neuronal stimulation changed according to the level of synaptic activity; when the frequency or intensity of the stimulus applied to presynaptic afferents was increased, the frequency of astrocyte oscillations was increased also. It is noteworthy that the increase in the stimulus rate determines a higher firing rate of neuronal afferents, whereas the increase in intensity may result in the recruitment of additional fibers that were not stimulated initially. The change in stimulus intensity or frequency probably causes an increased glutamate concentration in the extrasynaptic space and/or the activation of a higher number of localized $\left[\mathrm{Ca}^{2+}\right]_{\mathrm{i}}$ transients along processes of individual astrocyte that may account for the increased oscillation frequency in the astrocytes. These results provide a mechanism for a highly regulated and dynamic control on $\left[\mathrm{Ca}^{2+}\right]_{\mathrm{i}}$ oscillation frequency that depends on the integration of the $\mathrm{Ca}^{2+}$ signal deriving from these multiple sites of activation.

The inhibition of astrocyte $\left[\mathrm{Ca}^{2+}\right]_{\mathrm{i}}$ oscillations by TTX excludes that the response of astrocytes after the application of the stimulus to neuronal afferents could be attributable to a direct mechanical or electrical stimulation of the glial cells (Charles et al., 1991; Nedergaard, 1994). On the other hand, the finding that the mGluR antagonist MCPG blocked the astrocyte response to neuronal stimulation provides convincing evidence that synaptically released glutamate is responsible for astrocyte $\left[\mathrm{Ca}^{2+}\right]_{\mathrm{i}}$ oscillations. Further support for the synaptic origin of the stimulus inducing the $\left[\mathrm{Ca}^{2+}\right]_{\mathrm{i}}$ changes in astrocytes derives from the observation that in the presence of iGluR blockers the electrical stimulus failed to produce any response from neurons, whereas it did induce an oscillatory response in astrocytes. This result also suggests that activation of afferent fibers is sufficient for inducing astrocyte oscillations, thereby excluding the hypothesis that effects secondary to postsynaptic neuron activation are critical for astrocyte responsiveness.

Oscillations in astrocytes occurred with a delay with respect to the $\left[\mathrm{Ca}^{2+}\right]_{\mathrm{i}}$ increase observed in neurons. One possible explanation for this delay may be the time required for the diff usion of glutamate away from the synaptic cleft. With respect to the receptors at the neuronal postsynaptic membrane, those at the astrocyte membrane are relatively far away from the site of neurotransmitter release and are probably activated only when the concentration of glutamate in the perisynaptic space reaches a threshold level. Theoretical models, however, suggest that glu- tamate can diff use from the site of release for several micrometers and reaches concentrations of $>10 \mu \mathrm{M}$ in the perisynaptic space within 0.5-5 msec (Clements, 1996). This explanation can, therefore, hardly account for the delay observed in the astrocyte response. The delay may be attributable to the time necessary for the $\left[\mathrm{Ca}^{2+}\right]_{\mathrm{i}}$ change to spread from the site of activation, presumably in proximity of the synaptic cleft, to the cell body and to the occurrence of a spatial-temporal integration of the $\mathrm{Ca}^{2+}$ signal. Indeed, astrocyte membranes have been identified within $1 \mu \mathrm{m}$ from the spine synapses of the cerebellum (Chaudhry et al., 1995), and a similar anatomical pattern has been described in CA1 hippocampal region (Rothstein et al., 1994).

\section{Long-term changes in $\left[\mathrm{Ca}^{2+}\right]_{i}$ oscillation frequency mediated by neuronal activity}

A second intriguing property of astrocytes is the plasticity of their response to neuronal stimulation. When successive stimulations were applied to neuronal afferents, astrocytes adjacent to stimulated neurons displayed an increased oscillation frequency rather similar to that observed after repetitive $t$-ACPD stimulation. Apparently, the astrocyte response can be potentiated according to previous episodes of activity occurring at synapses in close proximity. This represents, therefore, an activity-dependent change previously considered an exclusive feature of neuronal cells. It is reminiscent of the activity-dependent increase in synaptic efficacy of excitatory synaptic transmission, the so-called long-term potentiation (LTP) (Bliss and Lomo, 1973). LTP is believed to represent, at the cellular level, certain aspects of learning and memory phenomena (Bliss and Collingridge, 1993). Although many questions still remain unresolved, substantial understanding exists on the cellular and molecular basis of LTP (Bliss and Collingridge, 1993; Kullmann and Singelbaum, 1995). In contrast, very little is known about the long-term change in the astrocyte response. Thus it may seem premature to compare the two phenomena. Nevertheless, besides the fact that glutamate is the principal mediator of both events, the potentiation of the astrocyte response appears to share with neurons at least two of the formal properties that characterize LTP, such as saturation and persistency. As to the first, we observed the failure of inducing potentiation in cells oscillating at high frequency at the very beginning. As to the second property, i.e., persistency, we demonstrated that the potentiation of the astrocyte response persisted for at least $3 \mathrm{hr}$. In contrast to these common aspects, the kinetics of the induction mechanism are very different: LTP occurs within milliseconds, whereas the potentiation in astrocytes appears much slower. This latter observation suggests that the plasticity in the astrocyte response likely is involved in the slow modulation of the neuron-astrocyte network actions. The slowness of a signaling system, based on $\left[\mathrm{Ca}^{2+}\right]_{i}$ oscillations and waves with respect to the rapidity of synaptic transmission, has been suggested to denote the modulatory role of astrocytes in brain function (Dani et al., 1992; Smith, 1994).

\section{On the functional role of $\left[\mathrm{Ca}^{2+}\right]_{i}$ oscillations in astrocytes}

The final and key question is the functional role of $\left[\mathrm{Ca}^{2+}\right]_{i}$ oscillations in astrocytes and the possible significance of their potentiation in response to repetitive episodes of neuronal activity. Our observation that $\left[\mathrm{Ca}^{2+}\right]_{i}$ oscillations in astrocytes are accompanied by $\left[\mathrm{Ca}^{2+}\right]_{\mathrm{i}}$ elevations in adjacent neurons, together with the finding that this response could be blocked, at least in a number of neurons, by iGluR antagonists, suggests that astrocytes 
in situ can release glutamate or a glutamate analog efficiently. Indeed, in a number of neurons the $\left[\mathrm{Ca}^{2+}\right]_{\mathrm{i}}$ increase induced by $t$-ACPD was blocked by NBQX and D-AP5, indicating that this effect was totally dependent on the activation of AMPA and NMDA receptors. The insensitivity to TeNT of $t$-ACPD-induced $\left[\mathrm{Ca}^{2+}\right]_{\mathrm{i}}$ increase in these neurons indicates that the neurotransmitter is released by neither presynaptic terminals nor other neurons and thus points to the astrocytes as the cells responsible for this release. In other neurons, the activation of AMPARs and NMDARs by glutamate as well as the direct simulation by $t$ ACPD of mGluRs expressed at the neuronal membrane are responsible for the $\left[\mathrm{Ca}^{2+}\right]_{\mathrm{i}}$ elevation induced by $t$-ACPD. Active synaptic terminals may, therefore, not only rapidly excite postsynaptic target neurons but, by triggering $\left[\mathrm{Ca}^{2+}\right]_{i}$ oscillations in astrocytes and governing their frequency, modulate the excitability of other neurons that are not activated synaptically but lay within the domain underlined by the actions of responsive astrocytes. Signaling transduction systems that are based on $\left[\mathrm{Ca}^{2+}\right]_{i}$ elevations as well as typical manifestations of neuronal plasticity such as LTP, which critically depend on both the degree of activity of presynaptic afferents and the $\left[\mathrm{Ca}^{2+}\right]_{i}$ rise in the postsynaptic neurons (Bliss and Collingridge, 1993), thus may be deeply modified by the activity of astrocytes. Interestingly, in GFAP mutant mice the induction of long-term depression of synaptic transmission in the cerebellum is impaired (Shibuki et al., 1996).

Stimuli that increase the $\left[\mathrm{Ca}^{2+}\right]_{\mathrm{i}}$ in cultured astrocytes have been demonstrated to cause a $\mathrm{Ca}^{2+}$-dependent release of glutamate from astrocytes that can affect the $\left[\mathrm{Ca}^{2+}\right]_{i}$ in adjacent neurons (Parpura et al., 1994a). Our results demonstrated that glutamate-mediated $\left[\mathrm{Ca}^{2+}\right]_{\mathrm{i}}$ elevations were repetitive in most of the neurons $(80 \%)$, thus suggesting that they may derive from a pulsating release of the neurotransmitter by astrocytes. The hypothesis could be proposed that each of the $\left[\mathrm{Ca}^{2+}\right]_{i}$ transients in oscillating astrocytes in situ could trigger an episode of release. In such a case the increase in the frequency of $\left[\mathrm{Ca}^{2+}\right]_{i}$ oscillations in astrocytes after repetitive episodes of neuronal stimulation ultimately might result in a higher glutamate release and thus in a higher or more extensive influence of astrocytes on neuronal excitability.

Interestingly, the increase in oscillation frequency was higher after repetitive episodes of neuronal stimulation than after repetitive stimulation with $t$-ACPD. The possibility that the physiological stimulus is more effective than the confined activation of mGluRs is supported by the observation that a higher potentiation in the response of the astrocytes on the second $t$-ACPD application was observed in astrocytes displaying $\left[\mathrm{Ca}^{2+}\right]_{\mathrm{i}}$ oscillations after neuronal stimulation applied between the two $t$ ACPD applications. Apparently, glutamate is a more powerful agent than $t$-ACPD in inducing the potentiation of the astrocyte response. The activation of other receptors besides the metabotropic GluR that probably follows the synaptic release of glutamate or a factor co-released with glutamate by synaptic terminals or derived from postsynaptic neurons, such as nitric oxide (Schuman and Madison, 1993), may account for this difference. The observation that in cultured astrocytes the application of nitric oxide synthase inhibitors inhibited the plasticity of the astrocyte response (Pasti et al., 1995) is in favor of this latter hypothesis.

The critical dependence of the $\left[\mathrm{Ca}^{2+}\right]_{\mathrm{i}}$ oscillation frequency in astrocytes on the pattern of neuronal activity, their long-lasting frequency change after repetitive stimulation, and the $\left[\mathrm{Ca}^{2+}\right]_{i}$ increases in neurons that follow astrocyte activation suggest the existence of a glutamate-mediated bidirectional communication between neurons and astrocytes that may uncover unexpected roles of astrocyte $\left[\mathrm{Ca}^{2+}\right]_{\mathrm{i}}$ oscillations in synaptic transmission.

\section{REFERENCES}

Barres BA (1991) New roles for glia. J Neurosci 11:3685-3694.

Barres BA, Koroshetz WJ, Chun L, Corey D (1990) Ion channel expression by white matter glia: the type-1 astrocyte. Neuron 5:527-544.

Berridge MJ (1993) Inositol trisphosphate and calcium signalling. Nature 361:315-325.

Bliss TVP, Collingridge GL (1993) A synaptic model of memory: longterm potentiation in the hippocampus. Nature 361:31-39.

Bliss TVP, Lomo T (1973) Long-term potentiation of synaptic transmission in the dentate area of anaesthetized rabbit following stimulation of the perforant path. J Physiol (Lond) 232:331-356.

Calabresi P, Benedetti M, Mercuri NB, Bernardi G (1989) Selective depression of synaptic transmission by tetanus toxin: a comparative study on hippocampal and neostriatal slices. Neuroscience 30:663-670.

Carmignoto G, Vicini S (1992) Activity-dependent decrease in NMDA receptor responses during development of the visual cortex. Science 258:1007-1011.

Charles AC, Merrill JE, Dirksen ER, Sanderson MJ (1991) Intracellular signalling in glial cells: calcium waves and oscillations in response to mechanical stimulation. Neuron 6:983-992.

Chaudhry FA, Lehre KP, van Lookeren Campagne M, Ottersen OP, Danbolt NC, Storm-Mathisen J (1995) Glutamate transporter in glial plasma membranes: highly differentiated localizations revealed by quantitative ultrastructural immunocytochemistry. Neuron 15:711-720.

Clements JD (1996) Transmitter time course in the synaptic cleft: its role in central synaptic function. Trends Neurosci 19:163-171.

Cornell-Bell AH, Finkbeiner SM, Cooper MS, Smith SJ (1990) Glutamate induces calcium waves in cultured astrocytes: long-range glial signaling. Science 247:470-473.

Dani JW, Chernjavsky A, Smith SJ (1992) Neuronal activity triggers calcium waves in hippocampal astrocyte network. Neuron 8:429-440.

Edwards FA, Konnerth A, Sakmann B, Takahashi T (1989) A thin slice preparation for patch-clamp recordings from synaptically connected neurones of the mammalian central nervous system. Pflügers Arch 414:600-612.

Gallo V, Patrizio M, Levi G (1991) GABA release triggered by the activation of neuron-like non-NMDA receptors in cultured type 2 astrocytes is carrier-mediated. Glia 4:245-255.

Ghosh A, Greenberg ME (1995) Calcium signaling in neurons: molecular mechanisms and cellular consequences. Science 268:239-247.

Glaum SR, Holzwarth JA, Miller RJ (1990) Glutamate receptors activate $\mathrm{Ca}^{2+}$ mobilization and $\mathrm{Ca}^{2+}$ influx into astrocytes. Proc Natl Acad Sci USA 86:3454-3458.

Jacob R (1990) Calcium oscillations in electrically non-excitable cells. Biochim Biophys Acta 1052:427-238.

Jeftinija SD, Jeftinija KF, Stefanovic G, Liu F (1996) Neuroligandsevoked calcium-dependent release of excitatory amino acids from cultured astrocytes. J Neurochem 66:676-684.

Kullmann DM, Singelbaum SA (1995) The site of expression of NMDA receptor-dependent LTP: new fuel for an old fire. Neuron 15:997-1002.

Martin DL (1992) Synthesis and release of neuroactive substances by glia cells. Glia 5:81-94.

Matteoli M, Verderio C, Rossetto O, Iezzi N, Cocco S, Schiavo G, Montecucco C (1996) Synaptic vesicle endocytosis mediates the entry of tetanus toxin into hippocampal neurons. Proc Natl Acad Sci USA 93:13310-13315.

Müller T, Grosche J, Ohlemeyer C, Kettenmann H (1993) NMDAactivated currents in glial Bergmann cells. NeuroReport 4:671-674.

Murphy TH, Blatter LA, Wier WG, Baraban JM (1993) Rapid communication between neurons and astrocytes in primary cortical cultures. J Neurosci 13:2672-2679.

Nedergaard M (1994) Direct signaling from astrocytes to neurons in cultures of mammalian brain cells. Science 263:1768-1771.

Palmer E, Monaghan DT, Cotman CW (1989) Trans-ACPD, a selective agonist of the phosphoinositide-coupled excitatory amino acid receptor. Eur J Pharmacol 166:585-587.

Parpura V, Basarky TA, Liu F, Jeftinija K, Jeftinija S, Haydon PG (1994a) Glutamate-mediated astrocyte-neuron signalling. Nature 369:744-747.

Parpura V, Fang Y, Basarky TA, Jahn R, Haydon PG (1994b) Expres- 
sion of synaptobrevin II, cellubrevin, and syntaxin but not SNAP-25 in cultured astrocytes. FEBS Lett 377:489-492.

Pasti L, Pozzan T, Carmignoto G (1995) Long-lasting changes of calcium oscillations in astrocytes. A new form of glutamate-mediated plasticity. J Biol Chem 25:15203-15210.

Pellicciari R, Luneia R, Costantino G, Marinozzi M, Natalini B, Jakobsen P, Kanstrup A, Lombardi G, Moroni F, Thomsen C (1995) 1Aminoindan-1,5-dicarboxylic acid: a novel antagonist at phospholipase C-linked metabotropic glutamate receptors. J Med Chem 38:3717-3719.

Pfrieger FW, Barres BA (1996) New view on synapse-glia interactions. Curr Opin Neurobiol 6:615-621.

Pin JP, Bockaert J (1989) Two distinct mechanisms, differentially affected by excitatory amino acids, trigger GABA release from fetal mouse striatal neurons in primary culture. J Neurosci 9:648-656.

Porter JA, McCarthy KD (1996) Hippocampal astrocytes in situ respond to glutamate released from synaptic terminals. J Neurosci 16:5073-5081.

Ramon y Cajál S (1911) Histology of the nervous system (American translation, 1995). Oxford: Oxford UP.

Rice ME, Pérez-Pinzón MA, Lee EJK (1994) Ascorbic acid, but not glutathione, is taken up by brain slices and preserves cell morphology. J Neurophysiol 71:1591-1560.

Romano C, Sesma MA, McDonald C, O’Malley K, van den Pol AN, Olney JW (1995) Distribution of metabotropic glutamate receptor mGluR5 immunoreactivity in the rat brain. J Comp Neurol 355:455-469.

Rossetto O, Gorza L, Schiavo G, Schiavo N, Scheller RH, Montecucco C (1996) Vamp/synaptobrevin isoforms 1 and 2 are widely and differentially expressed in non-neuronal tissues. J Cell Biol 132:167-179.

Rothstein JD, Martin L, Levey AI, Dykes-Hoberg M, Jin L, Wu D, Nash N, Kuncl RW (1994) Localization of neuronal and glial glutamate transporter. Neuron 13:713-725.

Scheenen WJ, Makings LR, Gross LR, Pozzan T, Tsien RY (1996) Photodegradation of indo- 1 and its effects on apparent $\mathrm{Ca}^{2+}$ concentration. Chem Biol 3:765-774.

Schiavo G, Montecucco C (1995) Tetanus and botulinum neurotoxins: isolation and assay. Methods Enzymol 248:643-652.

Schiavo G, Benfenati F, Puolain B, Rossetto O, Polverino de Laureto P,
DasGupta BR, Montecucco C (1992) Tetanus and botulinum-B neurotoxins block neurotransmitter release by proteolytic cleavage of synaptobrevin. Nature 359:832-835.

Schuman EM, Madison DV (1993) Nitric oxide as an intercellular signal in long-term potentiation. Semin Neurosci 5:207-215.

Seregi A, Keller M, Hertting G (1987) Are cerebral prostanoids of astroglial origin? Studies on the prostanoid forming system in developing rat brain and primary cultures of rat astrocytes. Brain Res 404:113-120.

Shibuki K, Gomi H, Chen I, Bao S, Kim JJ, Wakatsuki H, Fujisaki T, Fujimoto K, Katoh A, Ikeda T, Chen C, Thompson RF, Itohara S (1996) Deficient cerebellar long-term depression, impaired eyeblink conditioning, and normal motor coordination in GFAP mutant mice. Neuron 16:587-599.

Smith SJ (1994) Neuromodulatory astrocytes. Curr Biol 4:807-810.

Stratton KR, Worley PF, Baraban JM (1990) Pharmacological characterization of phosphoinositide-linked glutamate receptor excitation of hippocampal neurons. Eur J Pharmacol 186:357-361.

Szatkowski M, Barbour B, Atwell D (1990) Non-vesicular release of glutamate from glial cells by reversed electrogenic glutamate uptake. Nature 348:443-446.

Tsacopoulos M, Magistretti PJ (1996) Metabolic coupling between glia and neurons. J Neurosci 16:877-885.

Verkhratsky A, Kettenmann H (1996) Calcium signaling in glial cells. Trends Neurosci 19:346-352.

Watkins JC, Collingridge GL (1994) Phenylglycine derivatives as antagonists of metabotropic glutamate receptors. Trends Pharmacol Sci $15: 333-342$.

Watkins JC, Krogsgaard-Larsen P, Honoré T (1990) Structure-activity relationships in the development of excitatory amino acid receptor agonists and competitive antagonists. Trends Pharmacol Sci 11:25-33.

Woods NM, Cuthbertson KSR, Cobbold PH (1986) Repetitive transient rises in cytoplasmic free calcium in hormone-stimulated hepatocytes. Nature 319:600-602.

Zafra F, Lindholm D, Castren E, Hartikka J, Thoenen H (1992) Regulation of brain-derived neurotrophic factor and nerve growth factor mRNA in primary cultures of hippocampal neurons and astrocytes. J Neurosci 12:4793-4799. 